\title{
A METHOD FOR DETERMINING THE MOST FAVORABLE DESIGN OF GAS BURNERS
}

\author{
By John H. Eiseman, Elmer R. Weaver, and Francis A. Smith
}

ABSTRACT

The conditions which limit the satisfactory operation of a gas burner in its relation to the appliance are briefly discussed in a general way. Definite limits may be determined which show the conditions under which the flames flash back or blow from the ports and those under which combustion is rendered incomplete or "carbonizing" flames are produced. The relationships between these limiting conditions and several of the more important details of design and adjustment of the appliance are shown for the typical case of the top burner of a gas range burning a carbureted water gas of $570 \mathrm{Btu}$. The effects of the more important possible changes on the efficiency and rapidity with which heat is transferred are also shown, and the most favorable combination of conditions is systematically developed. The effects of the allowances which must be made in design for anticipated variations of pressure and inaccuracy of adjustment are also shown.

An appendix describes the laboratory apparatus which has been developed for experimental work of the kind involved.

\section{CONTENTS}

I. Introduction

1. Limits of operation of an appliance

2. General procedure in the design of an appliance........

II. Method of experimental study

1. Selection of the burner casting and the number of ports...

2. Determination of flash-back, blow-off, and yellow-tip limits and the effect of varying the port size on these limits...--

3. Determination of the limit of complete combustion and its variation with changes of distance between the burner and utensil

4. Determination of relative heating efficiency and its variation with changes of gas rate, primary air injection and distance between burner and utensil

5. The time required to perform a given heating operation and its effect on the selection of a proper distance between burner and utensil.

6. Normal air injection and its variation with orifice size

III. Effect of variations in gas pressure and of uncertainties in the adjustment of both gas rate and primary air on the safe range of primary air adjustment, the safe distance between burner and utensil and the heating efficiency obtainable . .

IV. Acknowledgment. . V. Appendix

1. An outline of the iodine pentoxide method for determining small quantities of carbon monoxide in the products of combustion

2. Application of the thermal conductivity method of gas analysis to the study of gas appliances....................

3. Burner testing apparatus used for supplying various adjustments of gas and primary air to a gas burner....... 


\section{INTRODUCTION}

The design and adjustment of a burner to give the most satisfactory operation, even when the composition of the gas to be supplied to the appliance is known and constant, is a complex problem. The Bureau of Standards was called upon to solve such a problem in the particular case of the top burner of a gas range to be supplied with propane, and subsequently has repeated the study with range burners for pure butane and for carburetted water gas of about $570 \mathrm{Btu}$. per cubic foot.

Although the use of a burner is rarely restricted to operation with gas of a definite composition, it is useful to know the design which would be the best for each of several such gases in order to determine the design of a burner which is to be used within an approximately known range of composition and service conditions.

This paper gives a detailed description of the method by which the best design for a given gas can be determined. From such a study it is possible to select the design and adjustment of a burner which will give the most satisfactory performance. Such performance includes a consideration of the efficiency of heating, the time required, and the safety of operation. Another paper now being prepared will contain a report of the results obtained by applying this method of study to each of several gases, such as the three listed above, from which the best design of burner for each can be obtained.

\section{LIMITS OF OPERATIOIN OF AN APPLIANCE}

A discussion of the conditions which limit the safe operation of an appliance, and their determination, is given in Bureau of Standards Technologic Paper No. 304, Method of Testing Gas Appliances to Determine Their Safety from Producing Carbon Monoxide. A portion of the discussion is repeated here because a thorough understanding of what these limits are and how they affect the operation of an appliance is absolutely essential to an understanding of the tests which follow.

Nearly all gas burners employed in domestic appliances are of the Bunsen or "blue flame" type and are commonly referred to as "atmospheric" burners. These burners are so designed that a portion of the air necessary for complete combustion mixes with the gas before it reaches the burner ports. This is called "primary" air. The additional air required is secured from the atmosphere surrounding the flames, and is termed "secondary" air. As the amount of primary air which mixes with a given amount of gas is increased, a limit is reached above which the flames either blow away from the ports or flash back into the burner, depending upon the gas rate used. Similarly, if the primary air is decreased, a limit is reached below which the color of the tip of the inner flame cone becomes yellow. This results from the formation of finely divided particles of solid carbon which do not burn nearly so readily as the gases from which they are formed. ${ }^{1}$

One of the principal requisites of a well designed appliance is that it be capable of burning completely the gas supplied to it, or stated

1 For a more complete discussion of the principles underlying these three conditions, see B. S. Circular No. 394 , pp. 3 to 8 . 
in another way, no incomplete combustion should result from any usual adjustment of gas or primary air.

A burner that is adjusted so that the flames are blowing away from the ports or have flashed back into the burner is not burning the gas completely. A flame having a yellow tip may also result in incomplete combustion and is objectionable in most cases because it may produce a carbon deposit on the material being heated.

Incomplete combustion may also result from other causes, such as inadequate combustion space, too little or improperly applied secondary air, etc., even when the burner is adjusted so that none of the other limits are encountered.

The quantitative determination and representation of these limits constitute the first part of the experimental work described in this paper. The application of the knowledge thus obtained to the problem of design is the next step.

Without doubt the limits of safe operation of an appliance are affected to some extent by barometric pressure. The results reported in this paper were obtained at sea level and should not be assumed to apply without modification to the operation of appliances at very high altitudes. The effect of altitude on the operation of appliances is a subject upon which future work is planned.

\section{GENERAL PROCEDURE IN THE DESIGN OF AN APPLIANCE}

A considerable portion of the field of burner design is covered in an elementary manner by Bureau of Standards Circular No. 394, entitled "Design of Gas Burners for Domestic Use." In that circular the various factors which affect a favorable design are pointed out, and their relationships are indicated in a qualitative manner. The method of investigation and analysis described in the present paper develops the important relationships quantitatively.

Because of the difficulty of making useful generalizations regarding the design of the many types of appliances in use, the discussion in Circular No. 394 was strictly limited to the burner itself to the exclusion of its environment, which was assumed to be predetermined. The present paper deals with the design of a burner for a specific application, "top burner" cooking, in which the utensils to be heated are supported by an open grate. The environment of the burner in this case is subject to one and only one important variation, the distance between the burner and the utensil heated. This paper therefore considers the position of the burner in addition to the design of the burner itself.

It is assumed in the discussion which follows that the reader is familiar with the fundamentals given in Circular No. 394, but for the reader who does not have access to the circular the necessary steps in designing a burner are again summarized in the approximate order in which they should be taken by quoting the summary of the circular.

Whether these steps can be followed in the exact order given depends upon which factors are known at the start. The order given assumes that nothing is known at first about the burner and that everything is known about the remainder of the appliance. There are many cases, however, in which some of the necessary characteristics of the burner may be known. For example, the proper size of port and the desired gas rate may be known, and if experience has shown that it is desirable to have a certain port area for this rate, then the number of ports and 
approximately the minimum size of the burner head could be determined from these facts. It is important to give all of the various factors sufficient consideration irrespective of the order in which they are taken. The summary of Circular No. 394 follows:

1. Determine the general shape and size of the burner from the space available and the manner in which the heat is to be applied.

2. Determine the arrangement of ports and provide for the escape of products of combustion with a view to insuring a uniform flow of secondary air to and away from each port with as little excess as is needed.

3. Determine the number and size of ports, making the number as large as can be provided for without excessive cost, and choosing a size which will permit a maximum of primary air without danger of either back-firing or lifting. As a general rule, trouble from back-firing will be avoided with manufactured gas if ports are drilled with No. 40 drills or smaller. Propane and butane permit the use of No. 32 drills, natural gas the use of No. 30 drills. This rule is subject to modification because of the conditions of use of the burner. If it is always supplied with gas at a uniform high rate, if there is no advantage in using much primary air, and if the burner is but slightly heated during use, the size of the ports may be increased with advantage. Burners which require much primary air, which become very hot, and which are likely to be turned low, must have smaller ports. To avoid the lifting of the flames, burners for manufactured gas

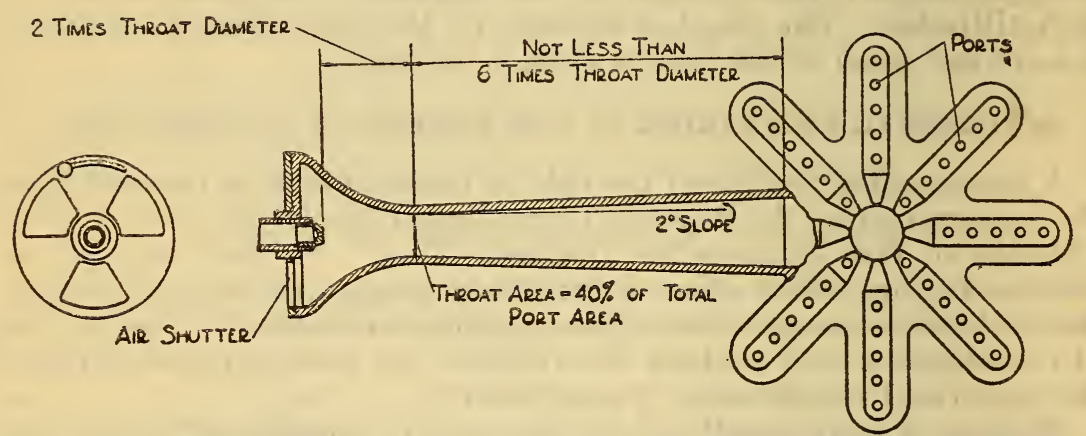

FIGURE 1.-Relative dimensions of a domestic gas burner to attain the maximum entrainment of primary air

should have at least 1 square inch of port area for each 25,000 Btu. per hour when gas is burned at the maximum rate. Burners for natural gas should have 1 square inch of port area per 10,000 Btu. per hour and burners for propane and butane 1 square inch per $12,000 \mathrm{Btu}$. per hour. These figures are subject to modification for the same reasons as are those for the size of ports.

4. Design the burner head of liberal size and with deep metal, through which the ports are machined.

5. Design the passages of the burner without abrupt changes in size or direction so that the stream of gas and air will expand gradually and approach the ports at low and uniform velocity. Make the area of the burner throat equal to about 40 per cent of the port area, and other dimensions of the mixer approximately as shown in Figure 1.

6. Select tentatively, for each of as many sets of conditions as seem necessary to cover the range of conditions in which the appliance is to be used, an orifice of area $a$, using the formula

where

$$
q=1,300 a \sqrt{\frac{h}{d}}
$$

$q$ is the maximum desirable volume of gas in cubic feet per hour,

$h$ is the maximum gas pressure in inches of water, and

$d$ is the specific gravity of the gas referred to air.

7. Assume the desired ratio of primary air to total air required for complete combustion from experience or from the discussion in this paper. 


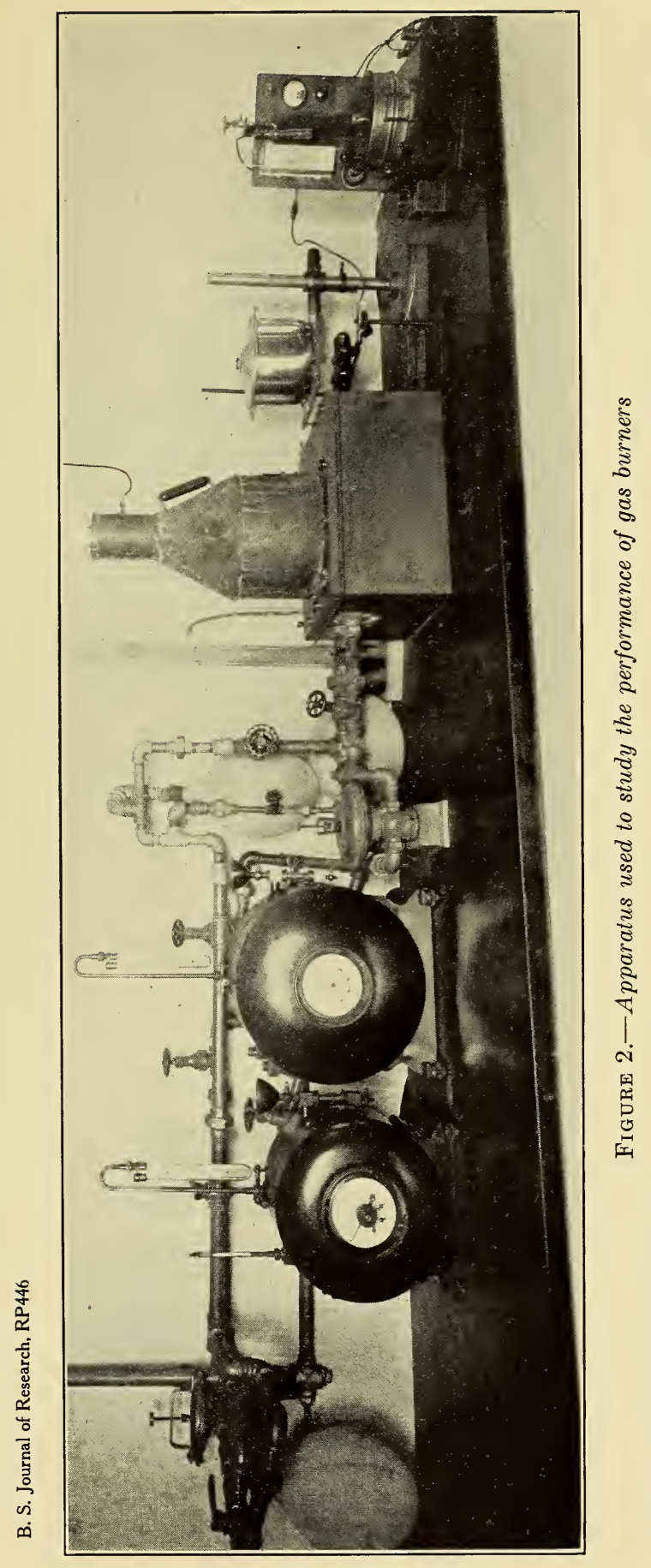


8. Assume a value for a burner constant $k$, from experience with a burner of the same general form or from the discussion in this paper (in the absence of any previous knowledge $k$ may be tentatively assumed equal to $0.6 \sqrt{P}$, where $P$ is the total area of the ports) and compute whether the burner tentatively planned will entrain the desired amount of primary air under each set of conditions assumed as representative of those to be met. Use the formula

$$
\frac{Q}{q}=k \sqrt{\frac{d}{a D}}
$$

or one of its modifications given in the discussion. $Q$ is the volume of primary mixture which flows per unit time, $q$ is the volume of gas which flows per unit time, $D$ is the specific gravity, referred to air, of the primary mixture, and $a$ and $d$ have the meanings stated in paragraph 6 . The constant $k$ is usually obtained by solving the same formula in which have been substituted values for the other symbols known from experience with a burner of similar form.

9. Having completed a model burner, determine by trial whether its performance is satisfactory within the range of air-shutter adjustment with respect to (1) completeness of combustion at the maximum rate of heat supply with the gas having the greatest requirement of "air for complete combustion," (2) back-firing with the most rapidly burning gas at minimum rate, and (3) lifting of the flames with the slowest burning gas at maximum rate.

10. Determine by trial the maximum primary air that will allow an ample factor of safety against unstable flames, and while using this high primary air place the burner or regulate secondary air to give as high efficiency as may be obtained while providing an ample factor of safety against incomplete combustion.

11. Select the orifice to be used with a particular gas supply by the aid of the formula given in paragraph 6 , or a corresponding one for the type of orifice used, if the orifice is known to give a result different from that of the formula. Then employ the formula stated in paragraph 8 , and a value of the burner constant $k$ determined by observation on the model under conditions as nearly as possible like those of service, and determine that the entrainment of primary air will be satisfactory within the range of adjustment of the air shutter. If the air required for complete combustion of the future supply of gas is not known, assume that 9 cubic feet of air will be needed per 1,000 Btu.

It will be apparent at once to the reader that certain very important details have been left to the judgment of the designer or to be determined by trial. Among these are the exact size of the ports, the location of the burner with respect to the object to be heated, and the proportion of primary air to be used. The most favorable values for these various quantities are related to one another, and also to such considerations as complete combustion and the efficiency and speed of accomplishing a desired operation, in such a way that they can not be determined independently but must be evaluated as a group if the best result is to be obtained.

Information of this nature is not always available and in such cases it is necessary to obtain it by actual test. Indeed, the values suggested in Circular No. 394 for use in the preliminary design of an appliance were in large part selected from a consideration of the results of tests reported for the first time in the present paper. It is hoped that the detailed discussion which follows will not only make it possible for a designer to obtain such information when desired, but will also give him a better understanding of the effect of changing different variables on the operation of an appliance.

\section{METHOD OF EXPERIMENTAL STUDY}

\section{SELECTION OF THE BURNER CASTING AND THE NUMBER OF PORTS}

In order to make this discussion as clear as possible, a complete description of the method of test will be given as applied to a gasrange burner to be used with manufactured gas. However, the method is equally applicable to other gases or other types of appliances. 
In this study it was required to design a "top burner" and make the most suitable adjustments of the burner for a gas range with open grate which was to be supplied with carburetted water gas of 570 Btu. per cubic foot.

The first step in design, the selection of the general size and shape of the burner head, was made somewhat arbitrarily. Past experience indicated that a star-shaped burner is superior to any other form employing drilled ports, for heating a utensil placed above it. A star burner permits secondary air to flow upward on both sides of every row of ports, and products of combustion to flow radially outward between rows of ports in a space that increases in width in proportion to the volume of the products. This arrangement results in a very favorable application of heat to the utensil, satisfactory aeration of the flame at each port, and a minimum of interference between secondary air and products of combustion, especially when the grate employed to support the utensil has the bars arranged radially. For these reasons a star burner was selected. The most favorable diameter for the burner, the number of its prongs, and the most favorable spacing of the ports may be made the subject of future investigation. These variables were not included in the present study because they were believed to be less important than several other factors which should be studied first and because their selection is dependent largely upon the cost of manufacture, which is not easily included in a quantitative way in a laboratory investigation. These considerations and the availability of a sufficient number of similar burner castings led to the choice for this work of an 8-prong star burner, $4 \frac{1}{2}$ inches in diameter and having 44 ports drilled in the manner shown in Figure 1. The castings met reasonably well the requirements of a good burner with respect to ability to entrain air and the distribution of pressure within the burner head.

\section{DETERMINATION OF FLASH-BACK, BLOW-OFF, AND YELLOW-TIP LIMITS AND THE EFFECT OF VARYING THE PORT SIZE ON THESE LIMITS}

The most desirable size of the ports is dependent upon the composition of the gas to be used, and to secure accurate information relative to the proper size for the given gas supply it was necessary to find quantitatively the effect of changes in port size on the position of the flash-back, blowing, and yellow-tip limits mentioned in the introduction. These limits are nearly independent of the position of the burner relative to the material heated. Efficiency, rate of heating, and the conditions under which combustion becomes incomplete are not thus independent, hence the conditions mentioned in the first group should be determined first, and the information obtained made use of to reduce the amount of work necessary in the study of the remaining conditions, as well as in the final selection of the most favorable combination.

In order to determine the conditions under which these three limits occur, the burner was installed so that both the gas rate and the supply of primary air could be varied at will. It was also essential to have suitable equipment for accurately controlling and measuring the rate of flow of both gas and air for each adjustment. Figure 2 shows the apparatus used for these tests. ${ }^{2}$ Having the burner installed in such

A detailed description of this apparatus is given in the Appendix. A brief discussion is also given in B. S. Tech. Paper No. 304. 
an apparatus and burning gas at a constant rate, the primary air was increased until the flames either lifted from the ports or flashed back into the burner. When this condition was reached the relative proportion of air and gas was determined. The primary air was next decreased until yellow appeared in the flame, and the ratio of air to gas again determined. The gas rate was then changed and the same procedure repeated. This procedure was continued until a series of tests had been made which covered the desired range of gas rates. The results obtained were plotted, using as the coordinates "Gas rate: thousands of Btu. per hour per port" and "Primary air: per cent of total air required." 3

Figure 3 represents the position of the boundaries of the regions in which flash back, blow-off or "lifting," and yellow tips occur in the

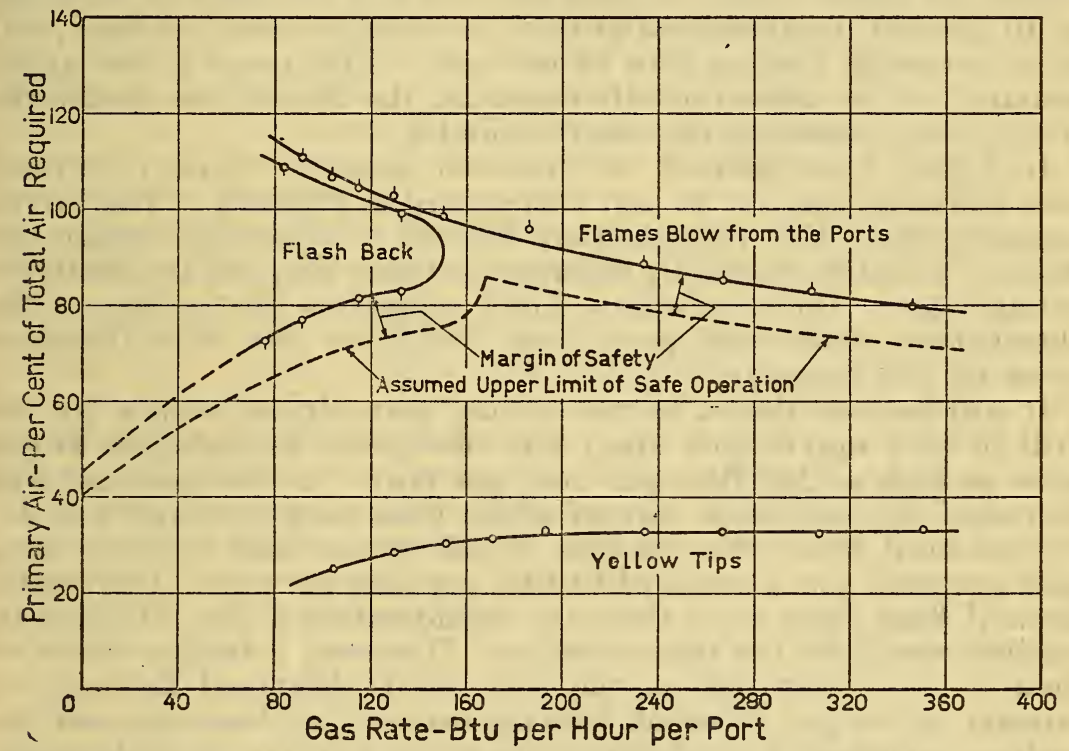

FIGURE 3.-Boundaries of the regions in which flash back, lifting, and yellow tips occur

Port size, No. 38. Carburetted water gas of $570 \mathrm{Btu}$. per cubic foot

case of ports drilled with a No. 38 (drill manufacturers' standard) twist drill (diameter, 0.1015 inch or $2.578 \mathrm{~mm}$. Area, 0.0081 in. ${ }^{2}$ or $5.23 \mathrm{~mm}^{2}$ ). The small circles with short lines pointing upward represent conditions under which the flames were observed to lift; those with short lines pointing downward represent conditions under which flash back was observed to occur; and circles without pointers represent the recorded appearance of yellow tips. Unfortunately, it is impossible with a multiple port burner and the experimental facilities used to determine the position of the flash-back curve at very low gas rates, but an unpublished study of flash back with a singleport burner under more accurately measurable conditions has established the shape of the flash-back curve, which is similar to the often

3 The choice of "Btu. per port" as the abscissa permits the application of the results directly to a burner having a different number or arrangement of well-aerated ports. The ordinate selected permits the most convenient intercomparison of different gases, the full advantage of which appears only in other papers in which such comparisons are of particular importance. 
published curves of flame velocity (usually rotated through an angle of $90^{\circ}$ ). The extrapolated portion of the curve is probably accurate enough for practical purposes, as will appear in connection with the discussion of Figure 5.

Since neither the flash back nor the lifting curve can be determined with absolute accuracy even under laboratory conditions, and still greater variations are encountered under conditions of use, it would be foolish to design an appliance to operate with exactly the highest air injection indicated by laboratory tests to be safe. It is therefore desirable to establish a margin of safety corresponding to the "factor of safety" usually assumed by engineers in designing mechanical structures. The margin of safety somewhat arbitrarily chosen is defined by reducing by 10 per cent the amount of primary air which causes the flames to lift at each gas rate and by similarly reducing by 10 per cent the amount of primary air which causes flash back, and then increasing the gas rate 10 per cent. This gives as the upper boundary of the region of safe operation the dotted lines below the curves which represent the observed limits.

In Figure 4 are plotted the observed limits for ports of several sizes including the No. 38 port represented in Figure 3 . The curves bounding the yellow-tip region are difficult to determine, within the limits of variation caused by differences of port size, and are relatively unimportant. Only one curve, which represents the average of the observations made with ports from No. 38 to No. 44 is therefore given for this boundary.

It will be seen that a burner having ports drilled with a No. 36 drill (0.0089 square inch area) was susceptible to flash back at gas rates as high as $216 \mathrm{Btu}$. per hour per port. As the port size was decreased the maximum rate at which flash back occurred was depressed until with a No. 44 drill $(0.0058$ square inch area) no flash back occurred above a rate of $40 \mathrm{Btu}$. per hour per port. Obviously, then, if flash back were the only consideration a No. 44 port, or smaller, would be the most suitable. However, a further study of these curves shows that as the port size is decreased the ratio of primary air to gas at which blowing occurs also decreases and the problem is presented of selecting ports which will give the best results, considering both flash back and lifting. To solve this problem it is necessary to introduce certain facts, learned from experience, the verification of which vill appear later in the paper.

It has been found tinat the highest efficiencies are possible if an appliance is designed to take the greatest amount of primary air that can be introduced without causing the flames either to lift or to flash back. Consider a burner that is supplied with both gas and primary air at constant rates, placed under a utensil that can be moved upward or downward at will. If the utensil is initially at a great distance from the burner there is no possibility that the utensil will interfere with the combustion of the gas, but very little of the heat produced by burning the gas will be transferred to the utensil; stated in another way, the "efficiency" will be very low. As the utensil is brought closer to the burner the efficiency increases, but a level is eventually reached at which the utensil does interfere with combusion, either through the effect of diminished temperature near its surface, or by preventing the access to the flames of enough secondary air, or both. If the utensil is left in the position at which incomplete combustion 
first appears and the supply of primary air is increased, combustion again becomes complete. Incidentally, the efficiency is diminished by this addition of primary air, but only to a small extent. If the utensil is again lowered, efficiency again increases. When incomplete combustion is again encountered the efficiency is found to be higher than when combustion became incomplete with the smaller amount of primary air. The process may be repeated with a closer approach of utensil to burner and an increase of efficiency for every addition of primary air until either flash back or lifting prevents further progress in this manner.

Another series of related facts must now be considered. A range burner is not always operated at the same gas rate; the gas is frequently, if not usually, "turned down" for the heating of small utensils, for gentle boiling, and for some other cooking processes. The burner must be adjusted to operate satisfactorily over the entire range of useful rates of heating without change other than the manipulation of the gas cock. To ascertain what single adjustment will permit this, it is necessary to determine the amount of primary air injected into the burner by gas supplied at different rates under the conditions of practical or "normal" use. A curve which represents the amount of air thus entrained in a burner with fixed adjustments when only the supply of gas is varied is commonly called, "a normal air-injection curve." Such a curve is determined by analyzing the mixture of gas and air that enters the burner under conditions of normal use. For the results to be completely significant, the orifice through which the gas is delivered and the opening of the air shutter, as well as the details of construction of the burner must be definitely known. If the size, form, or position of the orifice, the opening of the air shutter, the size or number of the ports, or the form of the burner is changed, a different normal air-injection curve will be obtained. However, it is important to note that a change in one of these details of design or adjustment, such as the size of the ports, great enough to make a decided change in the position of the normal air-injection curve affects the shape of that curve very little or not at all. Hence, a change in another detail, such as the opening of the air shutter, can usually be made which will bring the curve back to the position it had before any change was made.

This fact makes it possible to determine a series of normal airinjection curves with one burner, and to use these curves to predict with satisfactory accuracy the effect, on the amount of air injected, of varying the supply of gas to a burner of somewhat different design. Each of the normal air-injection curves of the one burner can be reproduced with the other burner by making suitable adjustments of orifice and air shutter.

In Figure 4 the observed positions of flash-back and lifting curves were shown. Instead of these, Figure 5 contains curves representing the assumed "upper limit of safety" obtained by allowing the margin of safety discussed in connection with Figure 3. To these curves are added a series of normal air-injection curves obtained with the burner drilled with No. 40 ports and corresponding to several adjustments of the orifice. For the reasons given above these curves may be assumed to apply satisfactorily to the burners with ports of other sizes also. It is therefore easy to determine from a study of Figure 5 the effect upon safety from flash back and lifting of any adjustment 


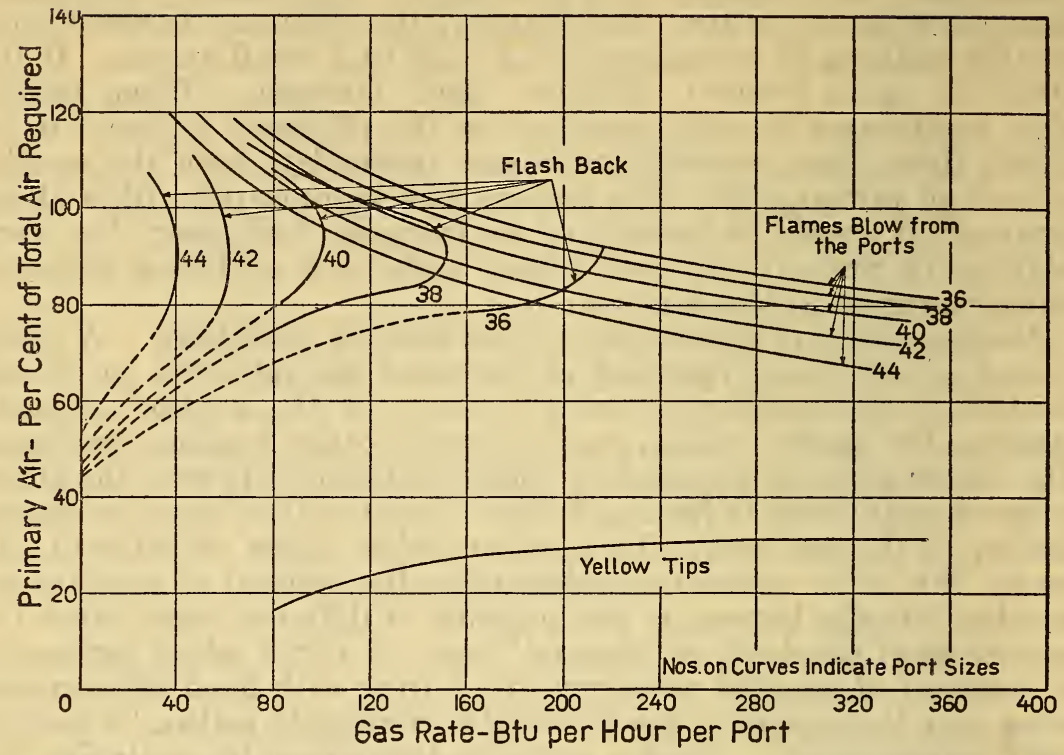

FIGURE 4.-Effect of the size of port on the position of the flash back, lifting, and yellow-tip curves

Port sizes, 36 to 44 .

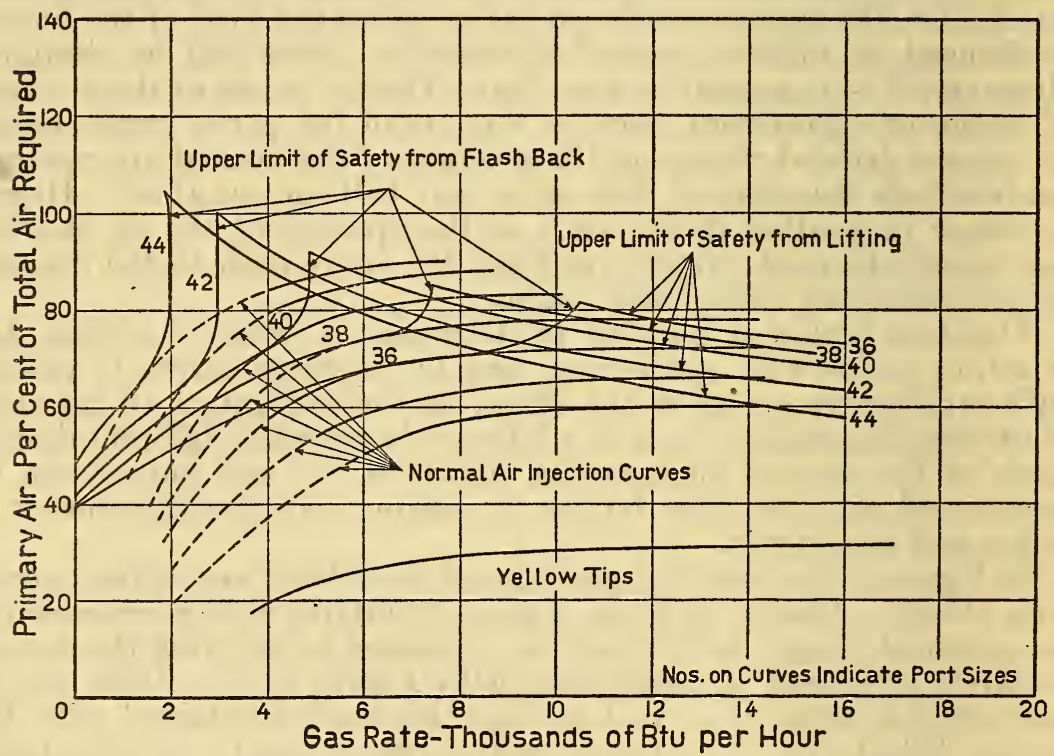

FIGURE 5.-The assumed safe upper limit of primary air

Port sizes, 36 to 44 . 
of burners of this form when drilled with ports of any size from 36 to 44 . We find, for example, that a burner with No. 36 ports is safe within the prescribed limits when burning gas at 12,000 Btu. per hour and when adjusted to entrain 78 per cent of the air necessary for complete combustion. If the burner so adjusted is turned down, however, there is danger of flash back below about 10,200 Btu. per hour. Obviously, no one would want a burner on a domestic range that could not be turned lower than 10,200 Btu. per hour; hence, if No. 36 drills are to be used, a considerably lower entrainment of primary air, about 72 per cent at 12,000 Btu. per hour, is necessary. This adjustment will permit an entrainment of only 58 per cent of the air needed for complete combustion at a gas rate of $4,000 \mathrm{Btu}$. per hour. If we use No. 44 drills we can turn down the burner to

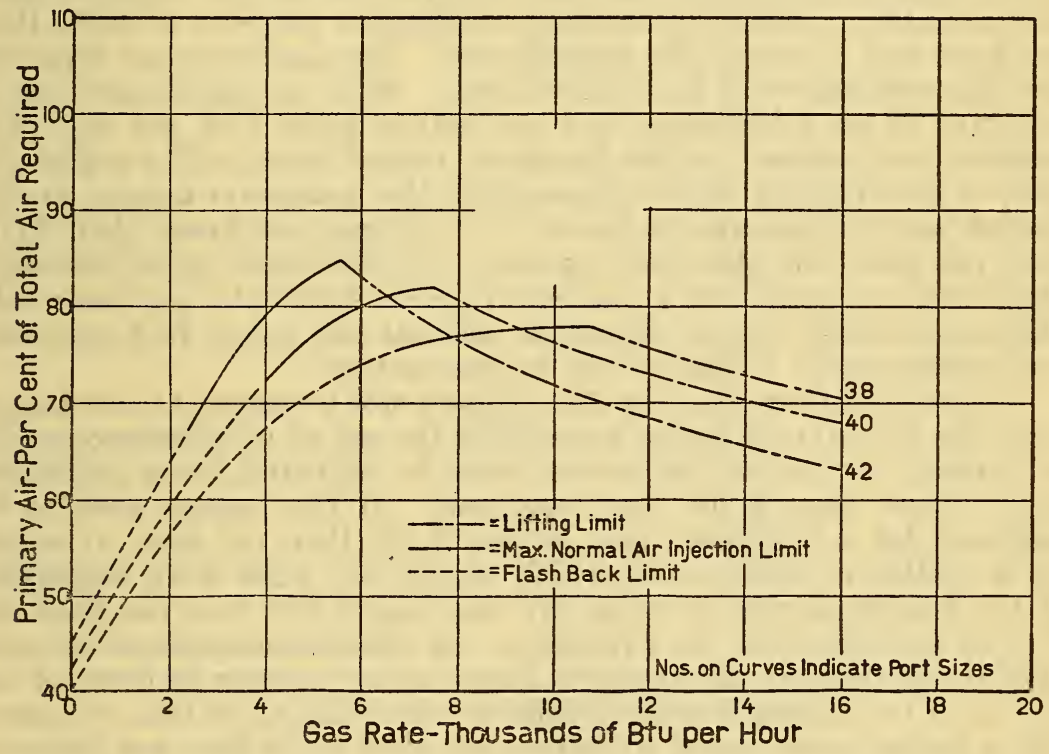

FIGURE 6.-The upper limit of safe adjustment of primary air for each gas rate

Port sizes, 38 to 42 .

any extent without danger of flash back if we adjust it to entrain 84 per cent of the air required at $4,000 \mathrm{Btu}$. per hour; but with such an adjustment we can use only about $4,500 \mathrm{Btu}$. per hour without danger of blowing off the flames. If the burner with No. 44 ports is to be used to supply 9,000 Btu. per hour, the usual maximum rate for a standard burner, it will have to be adjusted to inject at that rate only 70 per cent of the air required.

Since the greatest difficulty in burning gas completely is encountered when the rate at which it is supplied is greatest, we are primarily concerned with the air adjustment that may be made at the maximum gas rate, and that will still be safe for all other gas rates below the maximum. Figure 6 represents, for ports drilled with Nos. 38,40 , and 42 drills, the limit of safe adjustment of primary air at each gas rate, assuming that rate to be the highest but not the lowest that will ever be used. The curves are redrawn from Figure 5 on a larger 
scale to permit their easier inspection. Each limit is found, beginning at a high gas rate, such as 16,000 Btu. per hour, (1) by following the "upper limit of safety from lifting" for a given port size until it intersects the normal air-injection curve, which is tangent to the "upper limit of safety from flash back," for the same port size, (2) following this normal air-injection curve until the "upper limit of safety from flash back" is reached, and (3) following the latter curve to the zero rate

From these curves the maximum primary air for which it will be safe to make an adjustment can be obtained for any gas rate desired within the range covered. Having assumed a gas rate and determined the maximum primary-air injection, an orifice and air shutter setting which will give this injection will be safe to use at any rate lower than the assumed rate, but will not be safe at a higher rate. For example, suppose we assume a maximum gas rate of $9,000 \mathrm{Btu}$. per hour and a port of No. 40 drill size. The maximum air injection for this condition will be 78.5 per cent. With an adjustment which will give an air injection of 78.5 per cent at $9,000 \mathrm{Btu}$. per hour, the primary air injected as the burner is turned down will parallel the part of the limiting curve representing the maximum normal air injection and will always be below it. Any gas rate lower than 9,000 Btu. per hour will, therefore, be safe to use with such an adjustment. However, if the gas rate is increased above $9,000 \mathrm{Btu}$. per hour with this same orifice, the air injection will not fall below 78.5 per cent, and consequently lifting would be encountered.

It is seen at once that the No. 38 port size possesses an advantage over the No. 40 port size in permitting the use of a higher proportion of primary air when the burner must be adjusted for a maximum rate greater than 9,300 $\mathrm{Btu}$. per hour. If the burner were to be adjusted for a maximum rate of just $9,300 \mathrm{Btu}$. per hour, it would be a matter of indifference which of the two sizes were employed. If the maximum rate is to be any less than $9,300 \mathrm{Btu}$. per hour the No. 40 port size has the advantage. A similar comparison between the No. 40 and No. 42 port sizes shows the advantage in favor of the No. 40 if the burner is ever to deliver more than 6,500 Btu. per hour. For a burner constructed to deliver less than 6,500 Btu. per hour the No. 42 port size would have the advantage. Considering the probable use of a range burner of the "standard" size, the No. 40 port appears to be the most favorable size to use.

With the port size determined, the total port area is also fixed, and it is now possible to determine accurately the other dimensions, such as area of mixer throat, length of mixer tube, etc., using the relations as shown in Figure 1. These dimensions may now be changed on the test burner to meet the conditions for maximum air injection if desired. ${ }^{4}$

3. DETERMINATION OF THE LIMIT OF COMPLETE COMBUSTION AND ITS VARIATION WITH CHANGES OF DISTANCE BETWEEN THE BURNER AND THE UTENSIL

The above determinations have been concerned with the burner alone; the remaining tests consider the appliance as a whole, especially the relation between the burner and the combustion space, which, in this case, is the distance between the burner and the utensil.

- In this preliminary investigation for the determination of the proper port size, the design of the mixer is of small importance, as the primary air is forced into the burner. When the burner is placed in service, however, the primary air is injected into the burner by the momentum of the gas stream, and the design should be such that the air injection is within the range desired. 
The determination of whether or not combustion was complete was made by analyzing the products of combustion for carbon monoxide. ${ }^{5}$ In this study the relationship between the amount of gas burned and the smallest quantity of primary air which would insure complete combustion was determined.

With the burner installed as before, except that in this case a utensil was placed at some known distance above it, gas was supplied at a constant rate and an amount of primary air used which gave a flame adjustment just above the yellow-tip curve. After allowing sufficient time for conditions of temperature to become constant, a sample of the products of combustion was collected and analyzed for both carbon monoxide and carbon dioxide. At the same time the percentage of

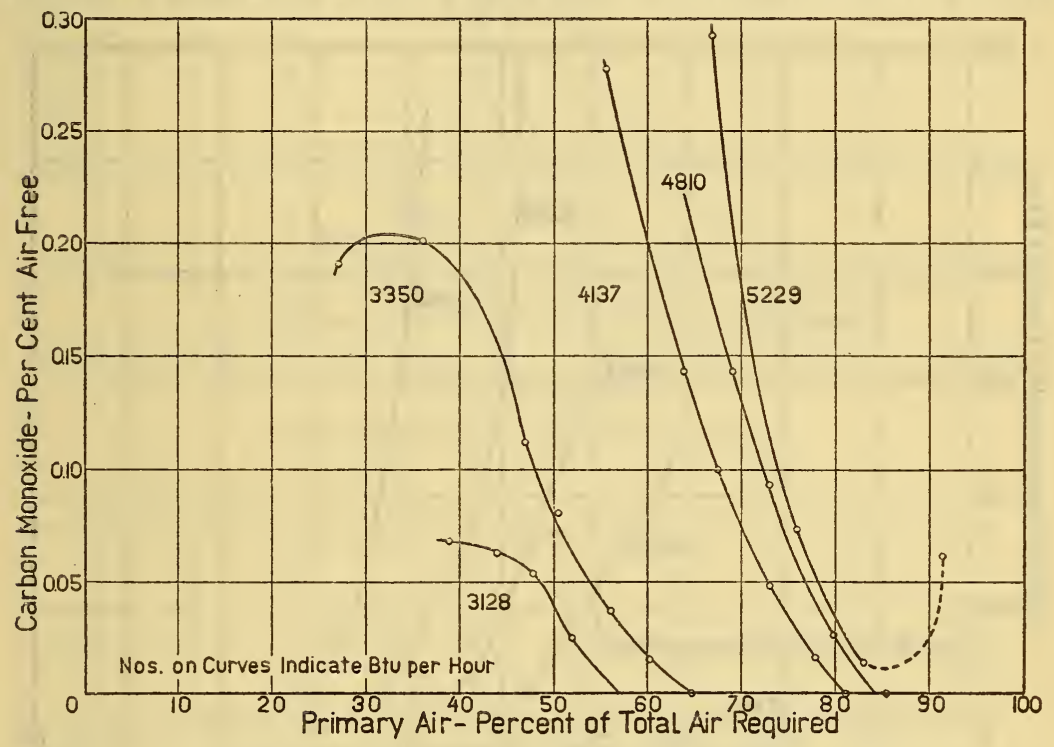

FIGURE 7.-The effect of primary air on the production of carbon monoxide at various gas rates

Distance between burner and utensil $=3 / 4$ inch

air in the mixture within the burner was determined. The primary air was now increased and the same procedure repeated. This procedure of increasing the primary air and analyzing the products of combustion was continued until an adjustment was made which resulted in the formation of very little, if any, carbon monoxide. Other determinations at various gas rates were made in the same manner. The percentage of carbon monoxide was reduced to an air-free basis by computation, the percentage of carbon dioxide in the sample and the theoretical percentage of carbon dioxide in the air-free products being known. This was done to correct for the amount of excess air drawn in at the time of sampling. The results were plotted as shown in Figure 7, all curves being extrapolated to the axis representing 0 per cent carbon monoxide.

- A description of the apparatus used for making these determinations is given in the Appendix. 
It will be observed that no amount of primary air would give a zero point when a gas rate of 5,229 Btu. per hour was used because the gas rate was too great for the distance used between burner and utensil, and lifting of the flames occurred before a zero point could be obtained. ${ }^{6}$ Figures 8 to 11 , inclusive, show similar studies, each chart giving the results obtained for a different distance between burner and utensil. From these charts the amount of primary air necessary to reduce the carbon monoxide to zero for any gas rate and distance used can be readily determined. These zero points from each chart were replotted as shown in Figure 12 and labeled " 0 per cent CO curves." The flash-back blowing, and yellow-tip curves obtained with the No. 40 port size and the "limit of safe adjustment" from Figure 6 were also plotted on this same chart, making it possible to

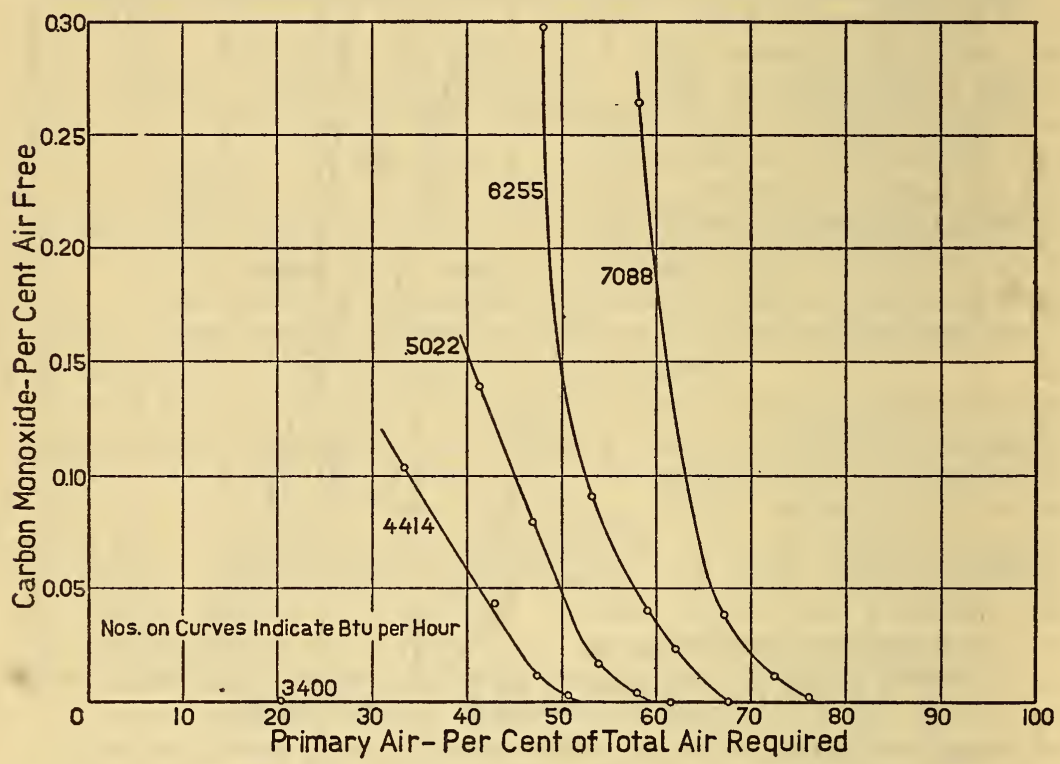

FIGURE 8:- The effect of primary air on the production of carbon monoxide at various gas rates

Distance between burner and utensil $=1$ inch

see at a glance within what limits the burner must operate to be satisfactory at any given distance between burner and utensil. For example, suppose it was desired to use a distance of $1 \frac{1}{4}$ inches, then for safe operation the burner must be adjusted for a condition which falls above the zero carbon monoxide curve for this distance, and at the same time falls below the limit of safe adjustment. It is seen immediately that the highest gas rate that can be safely used with the burner in this position is 9,200 Btu. per hour, and when adjusted for this rate 78 per cent of the air required for complete combustion must be supplied as primary air.

6 The somewhat peculiar condition occurring in this case, which may be called "smothering," is encountered only when products of combustion partially surround the flames and exclude the normal access of secondary air. It is not to be confused with the "blow-off" which occurs at a higher rate in the presence of abundant secondary air. 


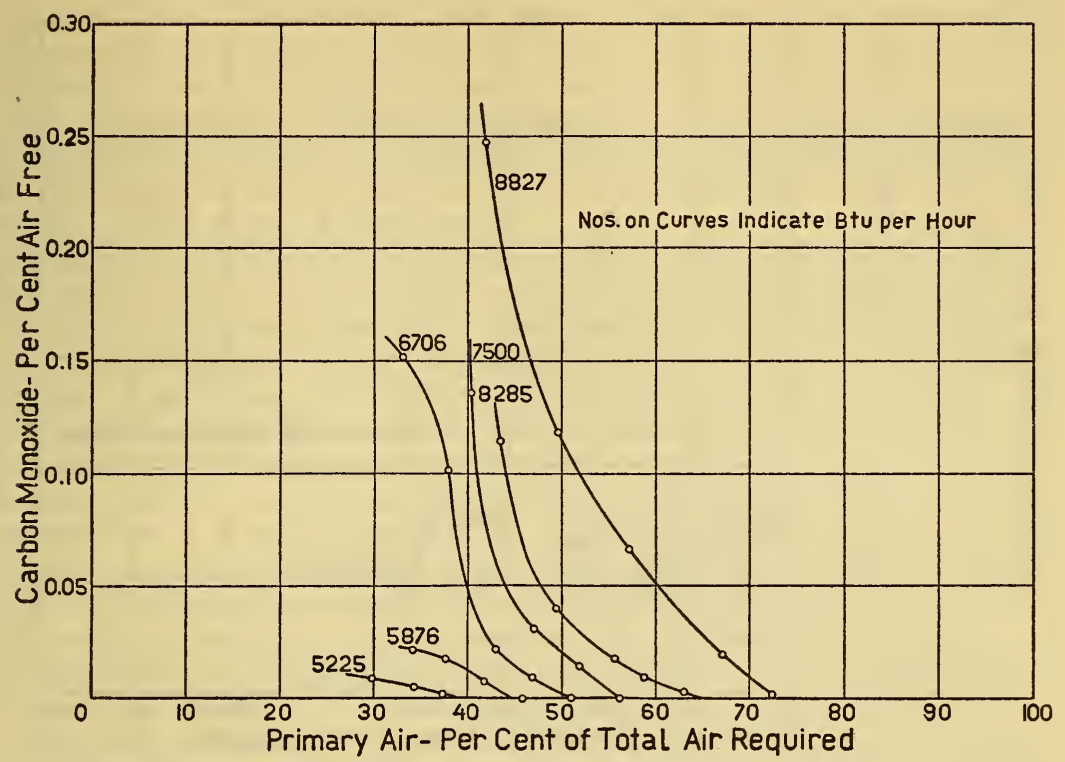

FigURE 9.-The effect of primary air on the production of carbon monoxide at various gas rates

Distance between burner and utensil $=1 \frac{1}{4}$ inches

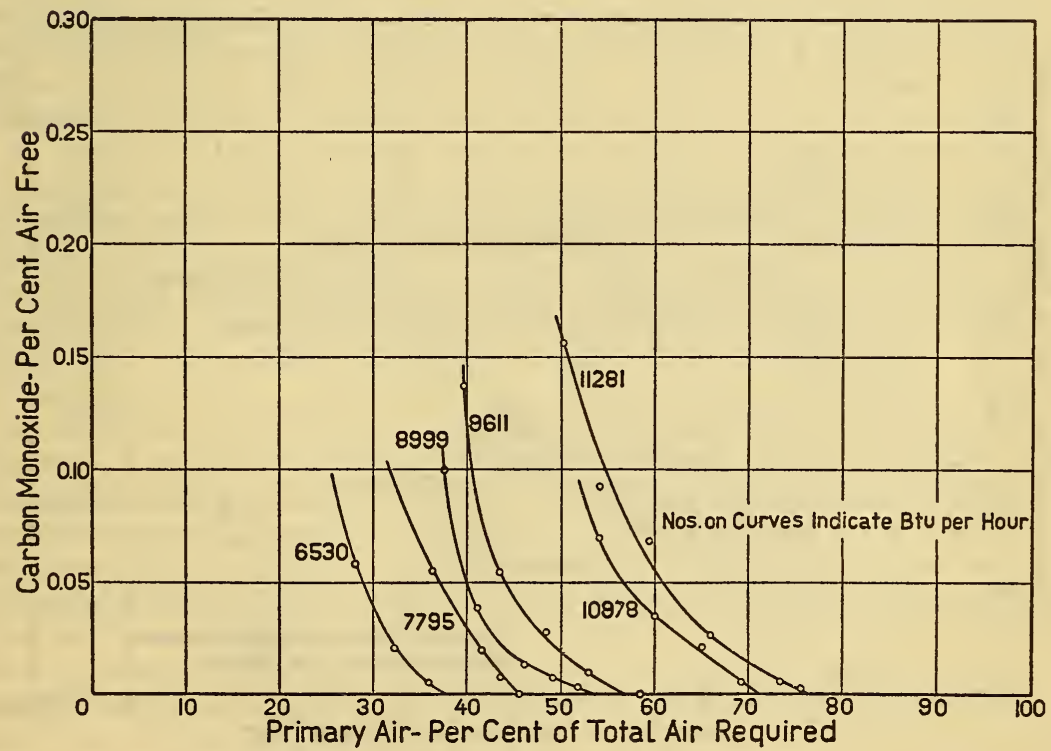

FIGURE 10.-The effect of primary air on the production of carbon monoxide at various gas rates

Distance between burner and utensil $=13 / 8$ inches 


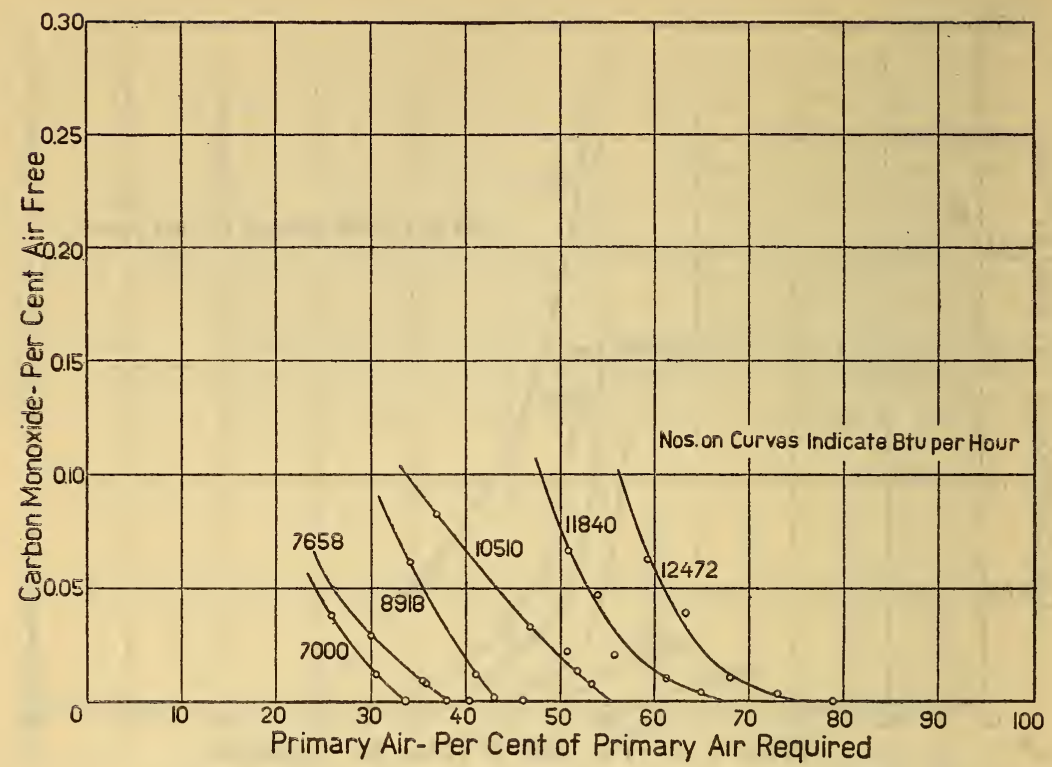

FIGURE 11.-The effect of primary air on the production of carbon monoxide at various gas rates

Distance between burner and utensil $=11 / 2$ inches

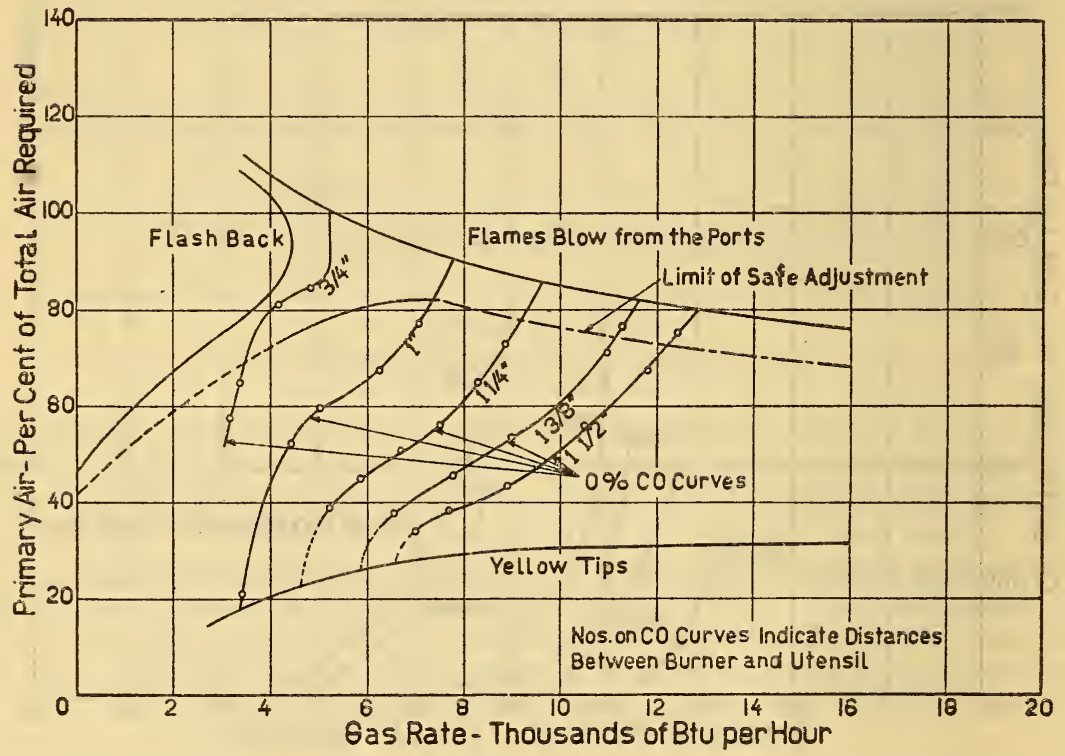

FIGURE 12.-Combined curves showing limits of saje operation at various distances between burner and utensil 
It is apparent that the farther the burner under investigation is removed from the utensil, the greater becomes the area of safe adjustment, and that a distance of three-fourths inch, or less, between burner and utensil is impracticable because of the extremely limited range of operation. The highest gas rate that could be used safely at this $3 / 4$-inch distance is $3,450 \mathrm{Btu}$. per hour (the rate corresponding to the intersection between the curves representing " 0 per cent $\mathrm{CO}$ " and the "limit of safe adjustment").

In order to show some of the information which can be gained from data such as are shown in Figure 12, several examples will be given.

1. What distance should be used between burner and utensil in order to burn gas at a rate of $9,000 \mathrm{Btu}$. per hour and with a burner capable of injecting only 55 per cent of the total air required? The intersection of the lines representing 9,000 Btu. per hour and 55 per cent primary air falls between the 0 per cent carbon monoxide curves obtained at $1 \frac{1 / 4}{4}$ and $1 \frac{3}{8}$ inch distances. In order to have complete combustion it would therefore be necessary to use a distance of $1 \%$ inches. A greater distance would also be safe, but would not give as high a heating efficiency. If the normal operating rate and the air adjustment are known, as is assumed in this example, then enough information is already available to select the proper distance between burner and utensil. If the burner is capable of adjustment to inject 78 per cent of the air required, however, the burner can be given this adjustment at $9,000 \mathrm{Btu}$. per hour and safely set $1 \frac{11 / 4}{4}$ inches from the utensil. It will then have a higher efficiency than when placed $1 \frac{3 / 8}{8}$ inches from the utensil. It is assumed in the discussion which follows, however, that the proper gas rate is one of the unknowns; and as the distance selected not only affects the efficiency but also the maximum rate at which gas can be safely burned and the time required to accomplish a given amount of heating, a consideration of these variables is also essential before a selection of distance can be made.

2. What is the permissible range of primary air adjustment when the burner is $1 \frac{14}{4}$ inches from the utensil and burning gas at a rate of 7,000 Btu. per hour? The lowest safe air injection is obtained by the intersection of the 0 per cent carbon monoxide curve for this distance and the line representing 7,000 Btu. per hour, while the highest is obtained from the intersection of the limit of safe adjustment and the $7,000 \mathrm{Btu}$. line. The permissible range is therefore from 52.5 to 82 per cent.

3. What is the maximum safe gas rate that can be used when the distance between the burner and the utensil is $13 / 8$ inches? The maximum safe gas rate is given by the intersection of the 0 per cent carbon monoxide curve obtained at this distance and the curve representing the limit of safe adjustment. This intersection occurs at a rate of $11,170 \mathrm{Btu}$. per hour. In order to use such a rate, however, it would be necessary to have the primary air adjusted for exactly 74.0 per cent of the total air required. A variation either way from this percentage would give an adjustment which would be either above the limit of safe adjustment or below the 0 per cent carbon monoxide curve, with either lifting of the flames or incomplete combustion as the result. A lower rate would therefore be necessary in practice, so as to allow a reasonable variation in primary air injection. 
4. DETERMINATION OF RELATIVE HEATING EFFICIENCY AND ITS VARIATION WITH CHANGES OF GAS RATE, PRIMARY AIR IN JECTION, AND DISTANCE BETWEEN BURNER AND UTENSIL

In addition to the factors which affect safety there are two conditions which every heating appliance must fulfill to be satisfactory to the user: (1) It must have a high heating efficiency, and (2) it must be capable of performing a given heating operation within a reasonable time.

Efficiency may be defined as the ratio of the heat transferred to the contents of the utensil to the total heat produced by the combustion of the gas. For example, the efficiency would be said to be 50 per cent if, when the gas is burned at the rate of 9,000 Btu. per hour, $4,500 \mathrm{Btu}$. is so transferred. In making a determination of efficiency, heat which goes to evaporate water from the utensil is included in that transferred. Heat which may have been transferred to the utensil, but is lost through radiation or otherwise than by causing evaporation, is not included.

The efficiency of heat transfer depends upon the size, shape, and material of the utensil and somewhat upon its temperature, which in turn depends to a certain extent upon its contents. It would be possible, therefore, to obtain a considerable variety of numerical values for efficiencies, depending upon the conditions employed during the tests. We are primarily concerned, however, with comparisons between one appliance and another rather than with absolute values. It is therefore sufficient for practical purposes to make the measurements of efficiency under a set of conditions chosen to approximate roughly the average service required of a range burner, and to reproduce carefully the same conditions in every test of a series that is to be intercompared. In the present study it was desired to determine how the efficiency is affected by variations in distance between burner and utensil, gas rate, and primary air injection. The method described below was selected because it is capable of giving the desired comparisons both accurately and with relatively few tests.

Two quarts of water (4.17 pounds) was heated to boiling. A reading of the gas meter was taken when the temperature reached $100^{\circ} \mathrm{F}$. and another at $200^{\circ} \mathrm{F}$. The difference between these readings (corrected to standard conditions) gave the amount of gas used in cubic feet, and this value multiplied by the heating value of the gas per cubic foot gave the Btu. delivered. The heat absorbed by the water in Btu. is the product of the number of pounds of water heated and the increase of temperature in degrees, and was the same in all tests, namely, $417 \mathrm{Btu}$. (In these tests the amount of water evaporated was negligible, and the heat required for evaporation was therefore not considered.) The efficiency was obtained by dividing the heat absorbed by the heat delivered, and multiplying the result by 100 . The time required for the temperature to rise $100^{\circ} \mathrm{F}$. was also recorded for each test. An aluminum utensil of light weight having a capacity of 4 quarts and a diameter of $63 / 4$ inches at the bottom was selected for these tests as being representative of the size and material most frequently used in the average family.

For these tests the burner was installed in the same manner as that employed for the study of combustion. With the utensil set at a fixed distance above the burner, a series of determinations of efficiency was made for each of several gas rates up to the maximum safe rate 
for the given distance, the primary air being varied over the entire range of safe air injections. (The maximum safe gas rate and the range of safe air injection were obtained from fig. 12.) The curves resulting when relative efficiencies are plotted against primary air, for each of four gas rates at distances of 1 inch and $1 \frac{14}{4}$ inches, are shown in Figure 13. Each point on the curves represents the average of two or more determinations.

The two short vertical lines shown on each rate curve are the limits of primary air injection within which the burner must be adjusted for safety from either lifting $(L)$, maximum normal air injection $(A)$, flash back $\left(F^{\prime}\right)$, carbon monoxide $(C)$, or yellow tips $(Y)$. For example, if a gas rate of 7,099 Btu. per hour is used with a 1 -inch distance between burner and utensil, the primary air must

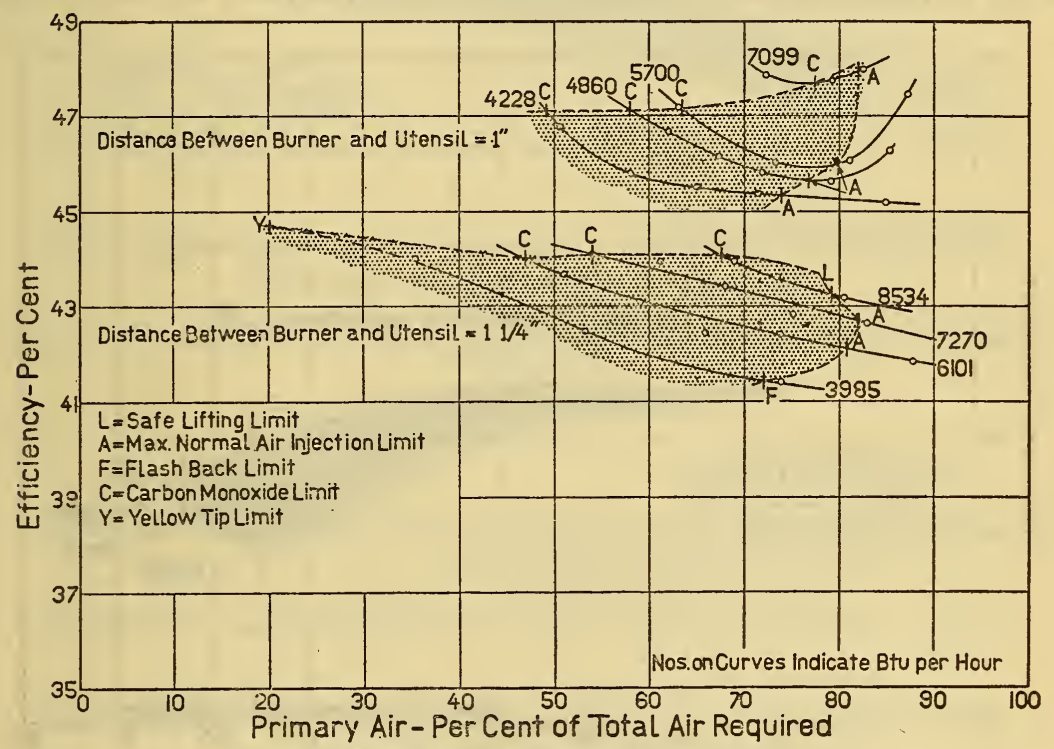

FIgURE 13.-Variation of heating efficiency with changes in gas rate, primary air injection, and distance between burner and utensil

Distances between burner and utensil $=1$ inch and $11 / 4$ inches

be adjusted between 77 and 82 per cent. (See fig. 12.) If the air injection falls below 77 per cent, as shown by the $C$ limit, then carbon monoxide will be produced, and if an adjustment is made to a higher value than 82 per cent, the flames will be in danger of flashing back when the "gas is turned down." At the highest gas rates lifting determines the upper limit of safe air injection. As the gas rate is decreased lifting is replaced by the maximum normal air injection as the upper limit of safety. This in turn is replaced by flash back at a still lower gas rate. Similarly, the gas rate used determines whether the production of carbon monoxide or the appearance of yellow tips determines the lower limit of safe air injection. By drawing a dotted line through all of the points representing the upper limits of safety and another through all of the points representing the lower limits and extending these lines until they intersect at a point 
representing the maximum safe gas rate, an area is delineated within which any efficiency shown can be safely obtained.

Results obtained in a similar manner, using $13 \frac{8}{8}$ and $1 \frac{1}{2}$ inch distances, are shown in Figures 14 and 15, respectively.

From Figure 12 it will be noted that the maximum safe gas rate which could be used at a 1-inch distance is 7,350 Btu. per hour, and if such a rate were used the primary air injection would have to be exactly 82 per cent for safe operation. Because the highest rate used in making the efficiency tests when using the 1-inch distance was slightly below this maximum gas rate, it was necessary to ascertain the efficiency which would have been obtained at $7,350 \mathrm{Btu}$. per hour by extrapolation. This was done by selecting from the curves of Figure 13 for the 1-inch distance the efficiencies which were obtained at the required primary air adjustment of 82 per cent, for each of the

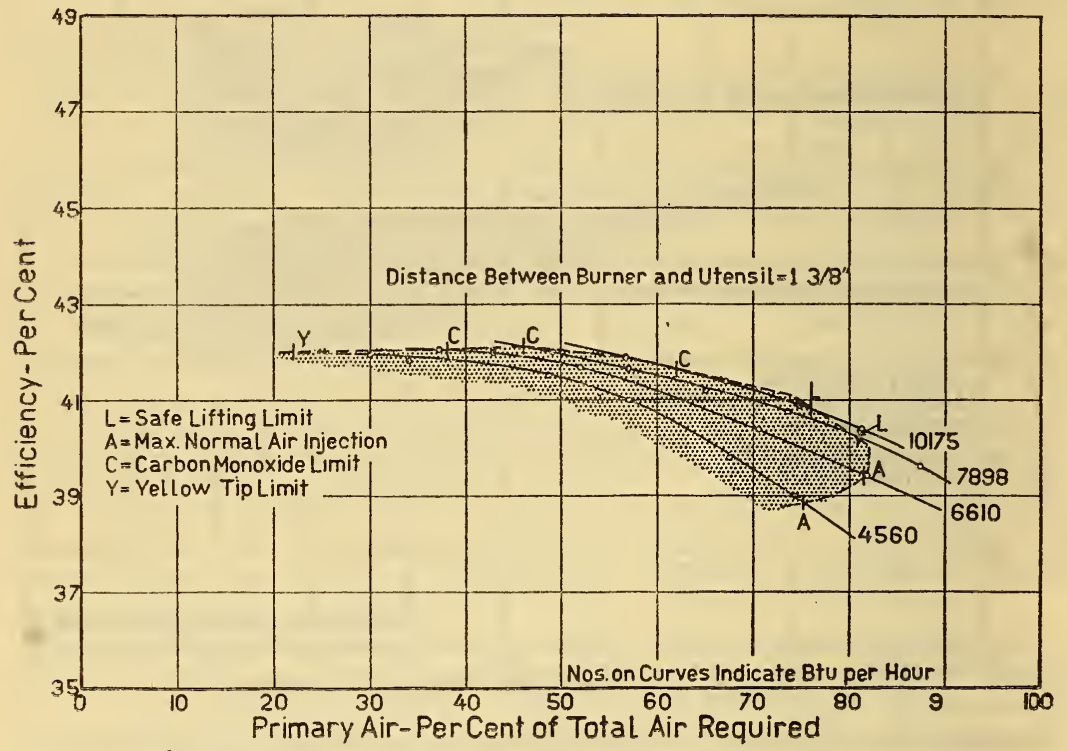

FIGURE 14.- Variation of heating efficiency with changes in gas rate and primary air injection

Distance between burner and utensil=13/8 inches.

several gas rates used. By plotting the efficiencies thus obtained against the corresponding gas rates and extrapolating this curve to the maximum safe gas rate, the efficiency which would have been obtained had such a rate been used was ascertained. Figure 16 shows the curves plotted in this manner for each of the four distances used, the maximum safe gas rate, and the required primary air adjustment being obtained in each case from Figure 12 .

It is realized that some error is introduced in such an extrapolation and that high accuracy would require an actual determination at this maximum adjustment. Such a setting, however, is extremely difficult to make and the additional accuracy attained would not be worth the time required. If the highest rate used in the tests is reasonably close to the maximum safe rate, the error caused by such an extrapolation is small. 


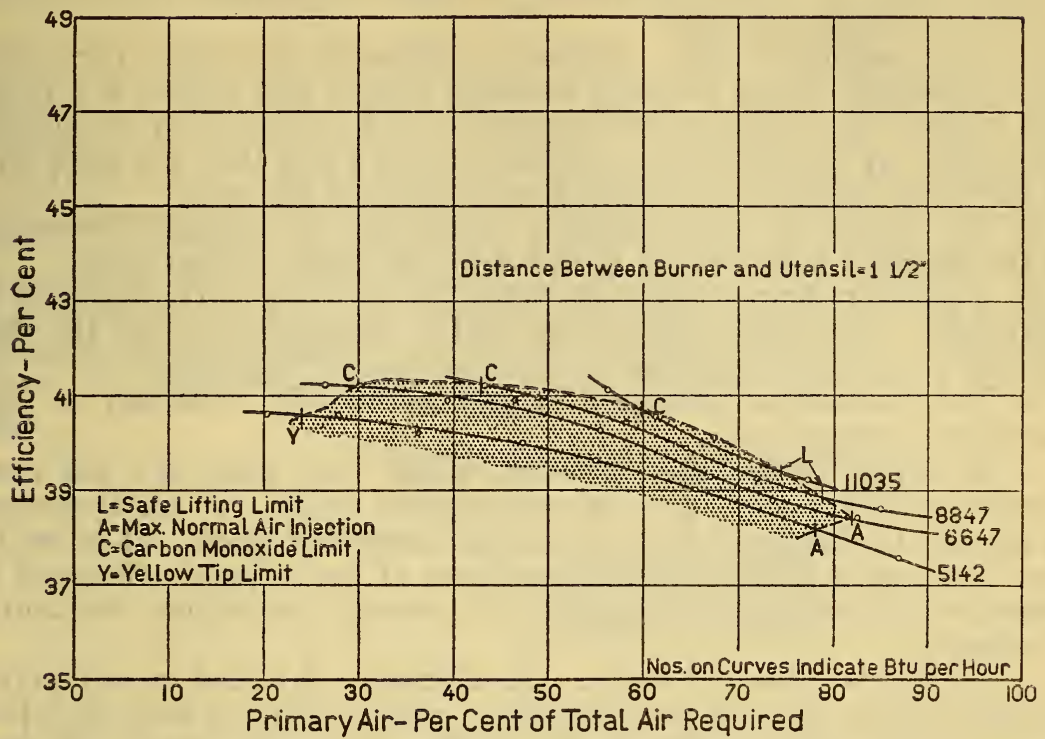

FIGURE 15.-Variation of heating efficiency with changes in gas rate and primary air injection

Distance between burner and utensil $=11 / 2$ inches.

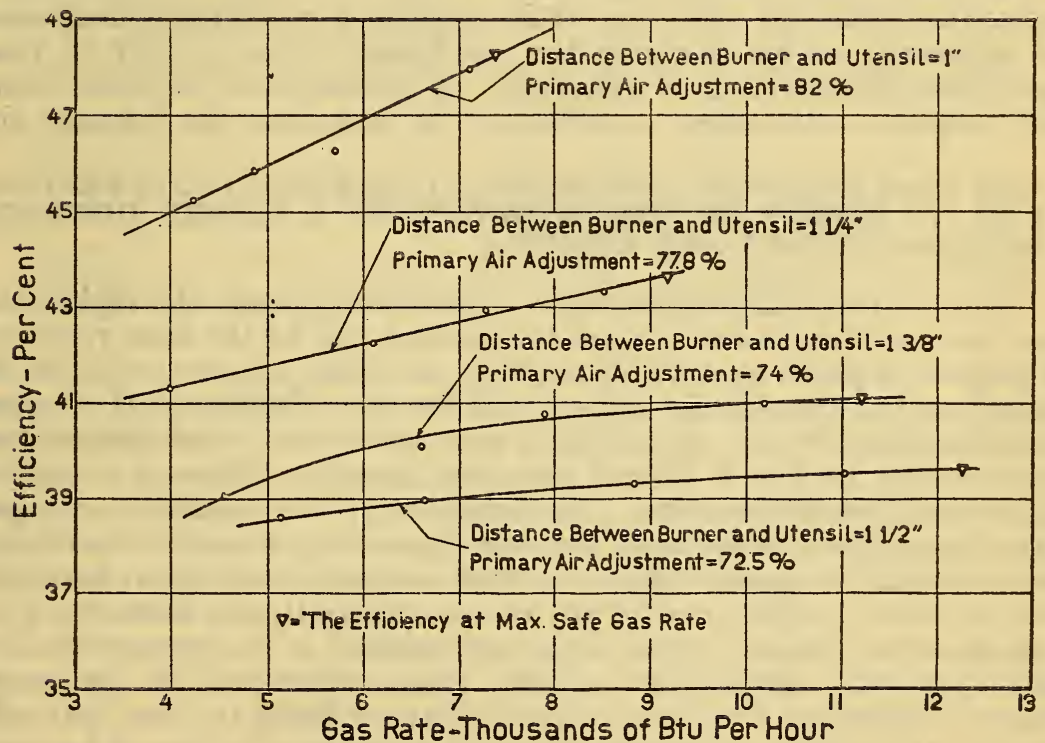

FIGURE 16.-Efficiencies obtained at the various gas rates used and with the primary air adjustment required at the maximum safe gas rate for each distance betwoen burner and utensil 
A summary of the information which can be obtained from Figures 13 to 16 , inclusive, follows:

1. The maximum safe efficiency attainable was 48.2 per cent. This is possible if the distance between burner and utensil is 1 inch, and in order to obtain this efficiency it would be necessary to operate the burner at the maximum safe gas rate of 7,350 Btu. per hour and to have the primary air adjusted at exactly 82 per cent.

2. The maximum safe efficiency which can be obtained decreases as the distance between the burner and the utensil is increased.

3. A greater range of safe gas rates can be used as the distance is increased. The advantage of this will be considered under the discussion of the time required for a given heating operation.

4. The maximum efficiency is not necessarily obtained at the maximum safe gas rate.

5. In actual service the efficiency would vary from 48.2 per cent downward, depending upon the adjustment made. In an appliance in service the distance from burner to utensil is fixed. It is easily seen that, at a given distance and rate of gas supply, efficiency is increased by reducing the amount of primary air, within the limits of safety.

6. As the gas rate is lowered, the efficiency obtained at any given air injection is reduced, but there is a greater range of safe air injection, as is shown in Figure 12. Stated in another way, for any setting of the air shutter in service (at a given setting the proportion of primary air is nearly constant), the efficiency is increased by increasing the rate at which gas is burned, within the limits of safety.

The effects on efficiency of changing the adjustments of appliances in service are thus clearly shown. It is evident that the common supposition that the efficiency of an appliance in service is decreased by adjusting, or by changing the conditions of gas supply so that more heat is delivered, is incorrect. A similar error is often made with respect to the effect on efficiency of increasing the primary air.

\section{THE TIME REQUIRED TO PERFORM A GIVEN HEATING OPERATION} AND ITS EFFECT ON THE SELECTION OF A PROPER DISTANCE BETWEEN BURNER AND UTENSIL

For any given distance between burner and utensil, the higher the gas rate that can be safely used the shorter will be the time required to perform a given amount of heating, while the closer the burner is placed to the utensil the higher will be the efficiency. If it were possible, therefore, to use as high a gas rate at the 1-inch distance as can be safely used at a $1 \frac{1}{2}$-inch distance, then the efficiency would be higher and the time shorter. Unfortunately, the maximum safe gas rate decreases as the distance between burner and utensil is decreased and since the increased efficiency thus obtained does not reduce the time as much as the lowered gas rate increases it, the final result of a decrease in distance over the range studied is an increase in the time required. These two effects must, therefore, be balanced against each other, the most suitable distance being the one that will produce the highest efficiency without increasing the time of heating beyond a certain predetermined value.

The selection of such a time limit is arbitrary and must be decided by the designer from the requirements of his particular problem. 
The relation between efficiency and time is shown in Figure 17. As previously mentioned, the maximum efficiency does not always occur at the maximum safe gas rate. Therefore, the maximum efficiency which can be obtained at any given distance does not necessarily correspond with the adjustment which would allow the transfer of a given amount of heat in minimum time. The only condition under which these two factors do correspond is that in which the maximum efficiency is obtained at the maximum safe gas rate. Accordingly, two efficiency curves are shown, one obtained by selecting as points the maximum safe efficiency at each distance and the other by plotting the efficiency obtained at the maximum safe gas rate for each distance, which is also the efficiency at minimum time. In the present study the 1 -inch distance is the only one at 盤:

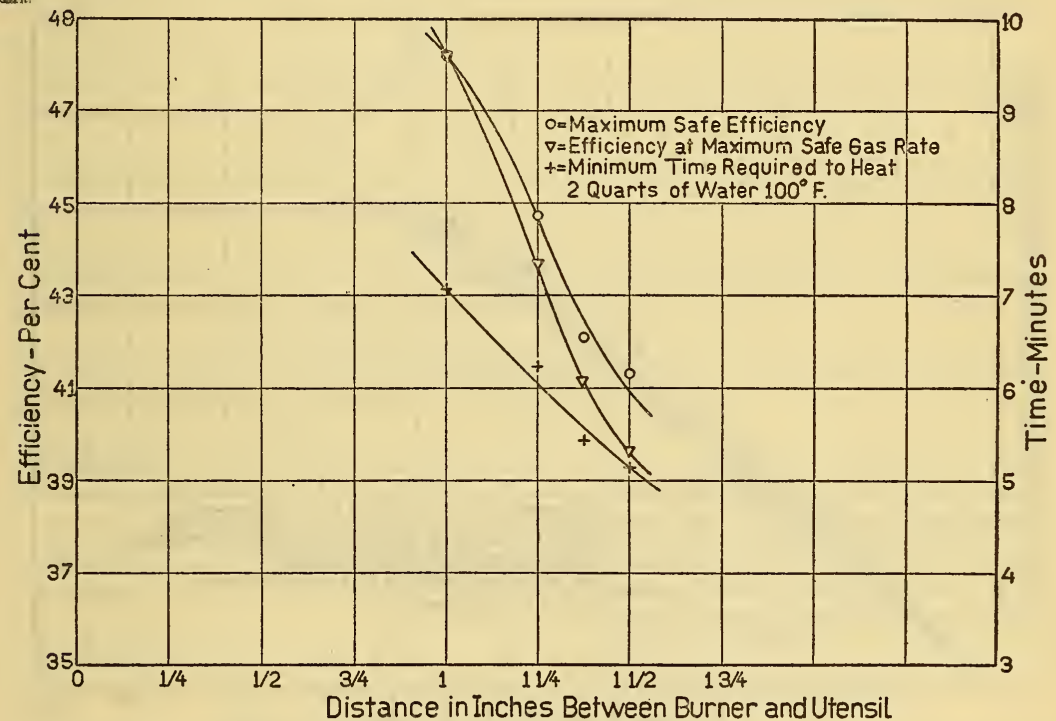

FIgURe 17.-The maximum safe efficiency and the efficiency at the maximum safe gas rate for each of the distances used. The minimum time required to heat 2 quarts of water $100^{\circ} \mathrm{F}$. at each of the distances used.

which these points exactly correspond. The time curve shown corresponds to the efficiency curve obtained from the maximum safe gas rate, which will, therefore, be the minimum time required. It is evident from this curve that the minimum time required to heat 2 quarts of water $100^{\circ} \mathrm{F}$. increases from 5.2 to 7.1 minutes $(37.3 \mathrm{per}$ cent) as the distance is decreased from $1 \frac{1 / 2}{2}$ inches to 1 inch. It is also apparent that a sacrifice of efficiency must be made if this increase in time is to be prevented.

Another method of representing these relations is shown in Figure 18 , where the gas rate in Btu. per hour is plotted against the heat absorbed in Btu. per hour. The heat absorbed is the product of the heat delivered in Btu. per hour by the efficiency. The point on each curve marked by a triangle is the maximum safe gas rate that can be used at the distance indicated. 
If we assume that we are able to adjust the gas pressure and hold it constant by means of a regulator or some other suitable device, it is now possible to select the best distance between burner and utensii, and also the proper gas rate to give the highest safe efficiency consistent with a reasonable time of heating.

In terms of heat absorbed per hour, any rate above $2,700 \mathrm{Btu}$. will be considered as satisfactory. ${ }^{7}$ Figure 18 shows that it is possible with the burner used to obtain much more rapid heating than this at any of the distances shown.

It is necessary to consider efficiencies as well as speed. In Figure 19 the maximum safe efficiency at each gas rate represented in the efficiency diagrams (figs. 13 to 15 ) is plotted against the corresponding rate of heat absorption. The solid lines are drawn to represent the

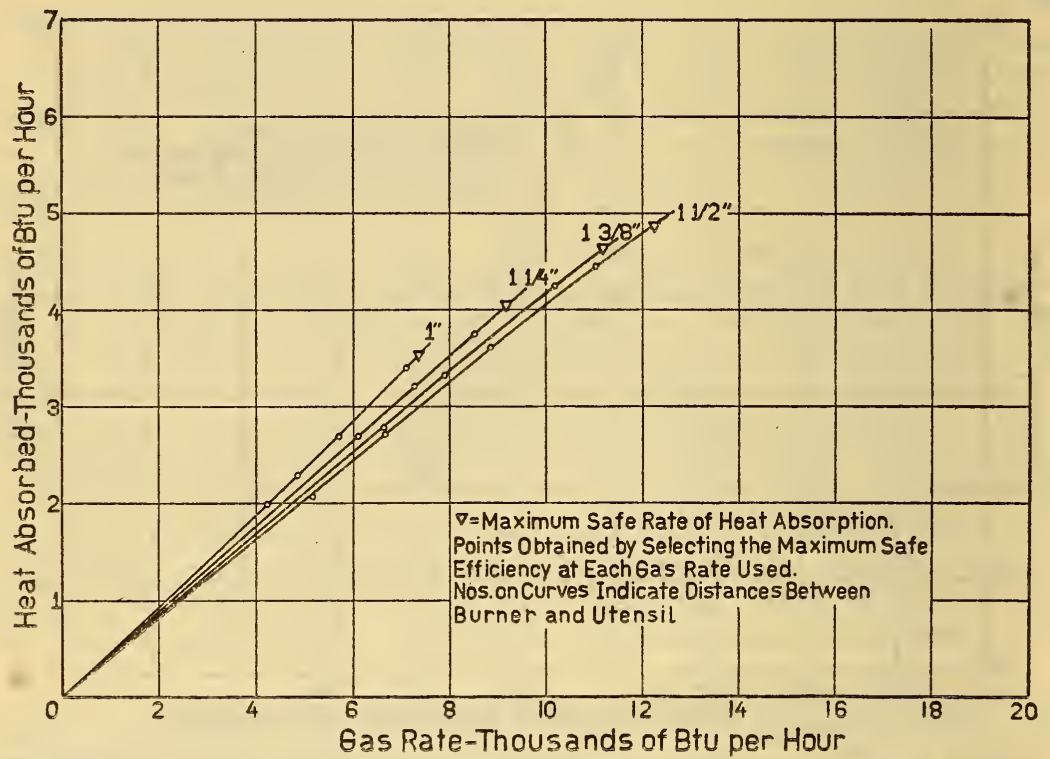

FIGURE 18.-Rate of heat absorption corresponding to the maximum safe efficiency at each gas rate used.

trend of these results. It will be observed that within the range of experiment the best efficiency obtainable at each distance between burner and utensil is nearly independent of the rate of heating, but tends at first to increase as the rate of heating is reduced, especially for the greater distances between burner and utensil. It must eventually fall to zero (at the rate required to maintain a temperature of $200^{\circ} \mathrm{F}$. in the utensil used in the efficiency test), but the lower parts of the curves have not been determined. If the appliance is adjusted for maximum efficiency at the maximum safe rate for heat transfer and subsequently turned down, as it would be in practice, without a readjustment of the air supply, the efficiencies follow the trend indicated by the crosses and the dotted lines. These data were obtained as follows: The maximum gas rate and the primary air required for

7 This limit is based on the "approval requirements" of the American Gas Association for gas ranges, which grants approval to appliances with standard burners which have an "input rating" of 9,000 Btu, per hour and an efficiency of 30 per cent. 
safe combustion were obtained from Figure 12. The corresponding point was located by following to the left the nearly horizontal curves in Figure 20, which represent the amount of primary air injected; the primary air at each rate as the burner is turned down was easily located. (The method by which the curves of fig. 20 were obtained is discussed in section 6.) Reference was then made to Figures 13 to 15 to determine the efficiency at the rates for gas and primary air in question. This efficiency was multiplied by the gas rate to determine the rate of heat transfer and the result plotted in Figure 19. Probably the most interesting result which appears from this figure is that under all conditions the efficiency decreases as the gas is turned down without changing the adjustment of air. Stated in another

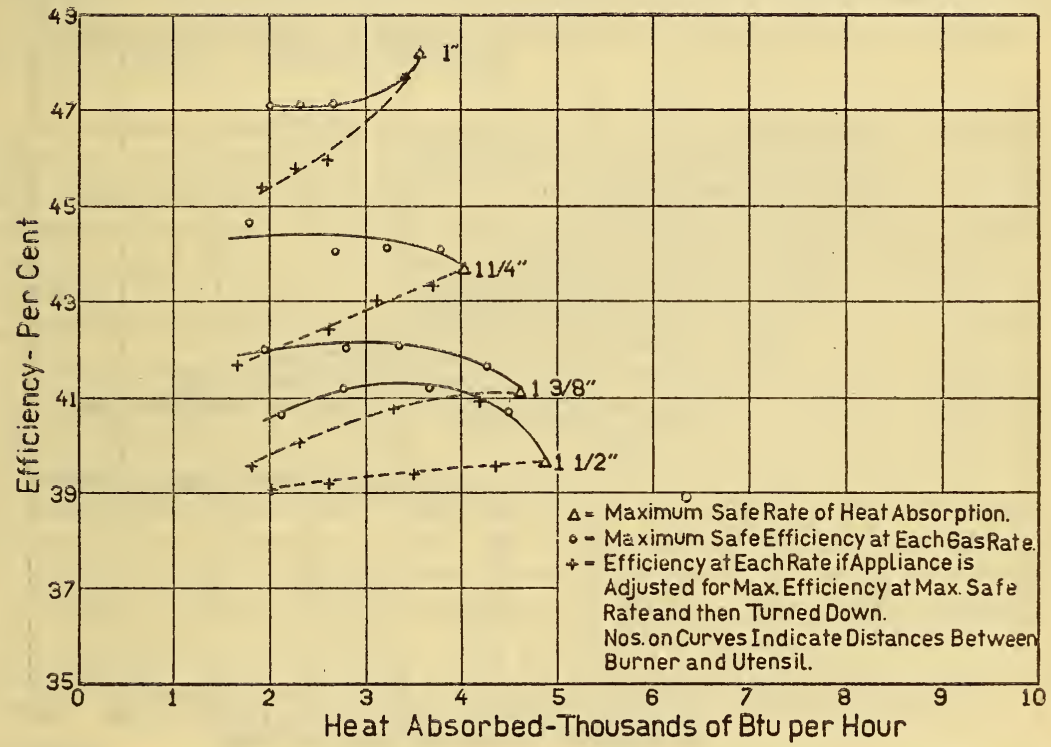

FIGURE 19.--Relation between efficiency and rate of heat absorption at each distance used

way, efficiency increases as the rate of heating is increased until the limit of safety is passed.

From Figures 18 and 19 it is apparent that the efficiency which can be obtained decreases but that the possible rate of heating increases as the distance between burner and utensil is increased. If speed were the only consideration, then the distance selected would be $1 \frac{1}{2}$ inches, but from the standpoint of economy it would be better to use a 1-inch distance, because the highest efficiency can be obtained at this distance and a satisfactory rate of heating as well.

With the pressure fixed it would be safe at this distance to use a gas rate of 7,350 Btu. per hour, which will allow a rate of heat absorption of $3,540 \mathrm{Btu}$. per hour and give a heating efficiency of 48.2 per cent.

The air injection required at a gas rate of $7,350 \mathrm{Btu}$. per hour at the 1-inch distance was previously determined from Figure 12 to be 82 per cent; it is now necessary to determine the size of orifice which will give this air injection. 


\section{NORIMAL AIR INJECTION AND ITS VARIATION WITH ORIFICE SIZE}

In all of the previous tests the orifice size was unimportant because the primary air was forced into the burner. It was merely necessary to use a size which would allow the gas to pass at the desired rate under the range of pressure available. However, when an appliance is installed for use, the primary air is drawn into the burner by the energy of the gas stream issuing from the orifice, and the amount thus injected depends in part upon the size of the orifice. When using any given rate of gas supply the amount of air injected increases as the size of the orifice is decreased.

For the determination of this relation the burner was connected to a source of gas supply only, the air mixer being left open to the air of

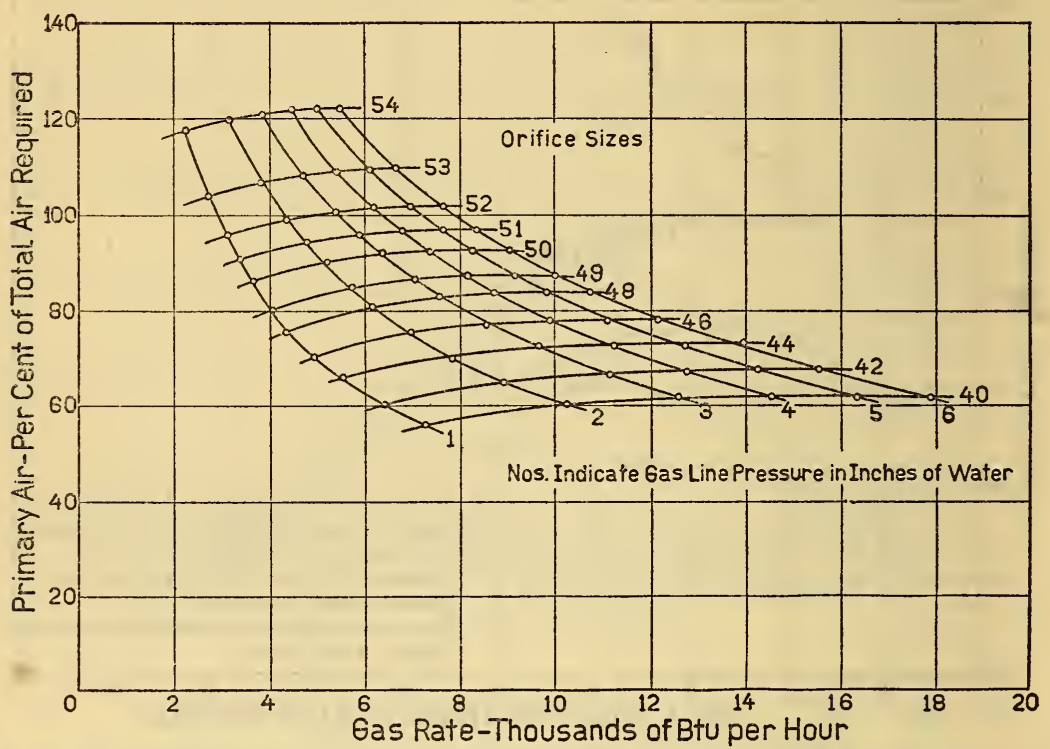

FIGURE 20.- The primary air injected by gas at different rates with various pressures and orifice sizes

the room. The burner used was provided with an air shutter, and this was set in its wide-open position. With an orifice of known size, ${ }^{8}$ the burner was then operated at a number of different gas pressures and the ratio of air to gas within the burner head and the gas rate were determined for each setting. The same procedure was repeated with orifices of as many different sizes as was desired. The results have been plotted in Figure 20, from which it is possible to select not only the proper orifice size to give the desired air injection, but also the gas pressure needed to give the desired gas rate.

From these curves it is apparent, for example, that the largest orifice which will give an air injection of 82 per cent when passing gas at a rate of $7,350 \mathrm{Btu}$. per hour is a No. 48, and the pressure necessary to

8 The results shown in Figure 20 were obtained by the use of a number of fixed orifices of different sizes. It is customary for most range manufacturers to supply the range with adjustable orifices. Such an orifice could be studied in the same manner as described above $r y$ making determinations at a number of different settings of the same orifice. 
deliver the gas at the required rate with this orifice is approximately $2 \%$ inches of water. If the pressure is below $2 \%$ inches, satisfactory entrainment of air is impossible with this burner at the 1-inch distance from the utensil, when using the desired gas rate, because carbon monoxide will be produced if the air injection is below 82 per cent. At a higher pressure a smaller orifice must be used to deliver gas at the desired rate, and the air shutter must be partially closed to control the amount of primary air, because lifting occurs above 82 per cent.

\section{EFFECTS OF VARIATIONS IN GAS PRESSURE AND OF} UNCERTAINTIES IN THE ADJUSTMENT OF BOTH GAS RATE AND PRIMARY AIR ON THE SAFE RANGE OF PRIMARY AIR ADJUSTMENT, THE SAFE DISTANCE BETWEEN BURNER AND UTENSIL, AND THE HEATING EFFICIENCY OBTAINABLE

It is obvious from the last paragraph that the appliance can not safely be constructed and adjusted to employ the optimum conditions unless both the pressure and the adjustment of primary air are subject to accurate control. The gas pressure in any given locality is usually variable, and unless some means for controlling this variation is available it is necessary to adjust a burner so that safe conditions will prevail over the range of pressures which will actually be encountered.

In order to allow for such fluctuations of pressure, the American Gas Association requires that the appliance be capable of meeting all of the requirements for safety when it is adjusted to deliver gas at the "normal" rate at one pressure and is then subjected to pressures 50 per cent above and below that for which the adjustment was made. Not only is it necessary to take practical account of the variations of pressure to which an appliance will be subjected, but it is also necessary to consider the uncertainty whether the primary air will be adjusted with the required accuracy. The problem of making suitable allowances for the effect of these variations which will be encountered in service can probably be most readily understood by considering an example.

Let us assume that the appliance has been adjusted to a gas rate which will permit the transfer of heat to the utensil at the "normal" rate of 2,700 Btu. per hour at the "normal" pressure of 3.5 inches. An inspection of Figure 19 shows that if the burner is placed 1 inch from the utensil an efficiency of 47.2 per cent will be obtainable. $2,700 \times \frac{100}{47.2}=5,710 \mathrm{Btu}$. per hour will therefore have to be supplied.

Referring back to Figure 13 we find that with this gas rate the maximum efficiency of 47.2 per cent is obtainable only when the primary air is reduced to 63.5 per cent, the limit of safety for gas burned at 5,710 Btu. per hour. With this rate the safe range of primary air lies between 63.5 and 80.0 per cent. If the pressure is to be increased 50 per cent, from 3.5 to 5.25 inches, without readjusting the appliance, gas will be delivered at the rate of $5,710 \sqrt{1.5}=7,000 \mathrm{Btu}$. per hour, and the adjustment of primary air must be such as to permit the satisfactory combustion of gas at this higher rate. Referring now to Figure 12, we find that at least 76 per cent of the air required must be introduced as primary air if gas is to be burned safely at 7,000 Btu. per hour. If the burner is adjusted so that 76 per cent of the air required is injected at a 
gas rate of $7,000 \mathrm{Btu}$. per hour, then at a gas rate of $5,710 \mathrm{Btu}$. per hour the appliance would inject 73 per cent of that required (this number is obtained by interpolating in fig. 5) instead of the $63.5 \mathrm{per}$ cent required to permit an efficiency of 47.2 per cent. This in turn reduces the available efficiency to 46.1 per cent at a gas rate of 5,710 Btu. per hour. (Fig. 13.) This lower efficiency corresponds to a rate of heat absorption of only $2,630 \mathrm{Btu}$. per hour. If 2,700 Btu. per hour is desired, the rate at which gas is supplied must be increased by a small amount. This process of trial and error can be continued until corresponding efficiencies, rates, and air adjustments have been determined with an accuracy as great as the experimental data justify. By such a series of approximations it is found that the appliance must be adjusted to take at least 5,860 Btu. per hour at the normal pressure of 3.5 inches with an efficiency of 46.1 per cent if heat is to be transferred to the utensil at the rate of 2,700 Btu. per hour and the operation of the appliance is to be safe without readjusting when the pressure is increased 50 per cent. After increasing the pressure 50 per cent the gas rate will be $7,180 \mathrm{Btu}$. per hour and the permissible air adjustment 79 to 82 per cent. (See fig. 12, 1-inch distance.) To keep within these limits of primary air at the higher pressure, the appliance will have to be adjusted at normal pressure to take primary air between the limits of 77 and 80 per cent of the total air required.

There is very little chance that in practice the adjustment of primary air will be made within this degree of accuracy. Appliance adjusters usually regulate primary air by their judgment of how the flame should appear, and there is not much difference in the appearance of the flame when primary air varies from 60 to 80 per cent of that required for complete combustion. It is therefore necessary to provide unusual means to insure correct adjustment in service, or to make the distance greater and so sacrifice the efficiency obtainable when the utensil is placed close to the burner.

By a series of approximations like that used for the 1-inch distance between burner and utensil the permissible range of air adjustments (shown by the distance between the curves representing the upper and the lower safe limits for primary air) may be found for each of the other distances for which data are available, and for other ratios of maximum pressure to pressure at the time of normal adjustment. The data obtained are plotted as solid lines in. Figure 21. This figure enables one to see at a glance the effect of any variation in pressure conditions on the permissible air adjustment.

Referring to the example discussed above in which the maximum pressure was assumed to be 1.5 times the pressure at normal adjustment, the permissible variations in primary air corresponding to this condition, at the various distances used, are shown by the solid curve marked "1.5." From the same figure it is easy to determine what will be the effect of any inaccuracy in the adjustment of either the gas rate or the air injection by the appliance adjuster. If the gas rate is likely to be set higher than intended by the designer, the effect may be allowed for by considering the pressure required to produce the excess as an increment to be added to the maximum pressure and correspondingly increasing the ratio of the maximum pressure to that at normal adjustment. We may make allowance for the error anticipated in the adjustment of primary air by drawing curves parallel to and within the limiting curves of Figure 21, at 
distances from them corresponding to the assumed uncertainty in this operation. As an example, it will be assumed that the maximum pressure will not exceed the pressure at the time of adjustment by more than 50 per cent. If there is no error in adjustment, the limit of safe adjustment would be within the solid curve marked " 1.5 " in Figure 21. Dotted lines are drawn showing the limits within which the workman should attempt to adjust the primary air if he is likely to make an error of 10 per cent of the total air required for complete combustion in either direction from the adjustment attempted. Thus, if the burner is set $1 \frac{1 / 4}{4}$ inches from the utensil, the air must be adjusted between 53 and 80 per cent for safety. The dotted curve represents the assumption that the adjuster will always stay within these limits if he tries to adjust between 63 and 70 per cent.

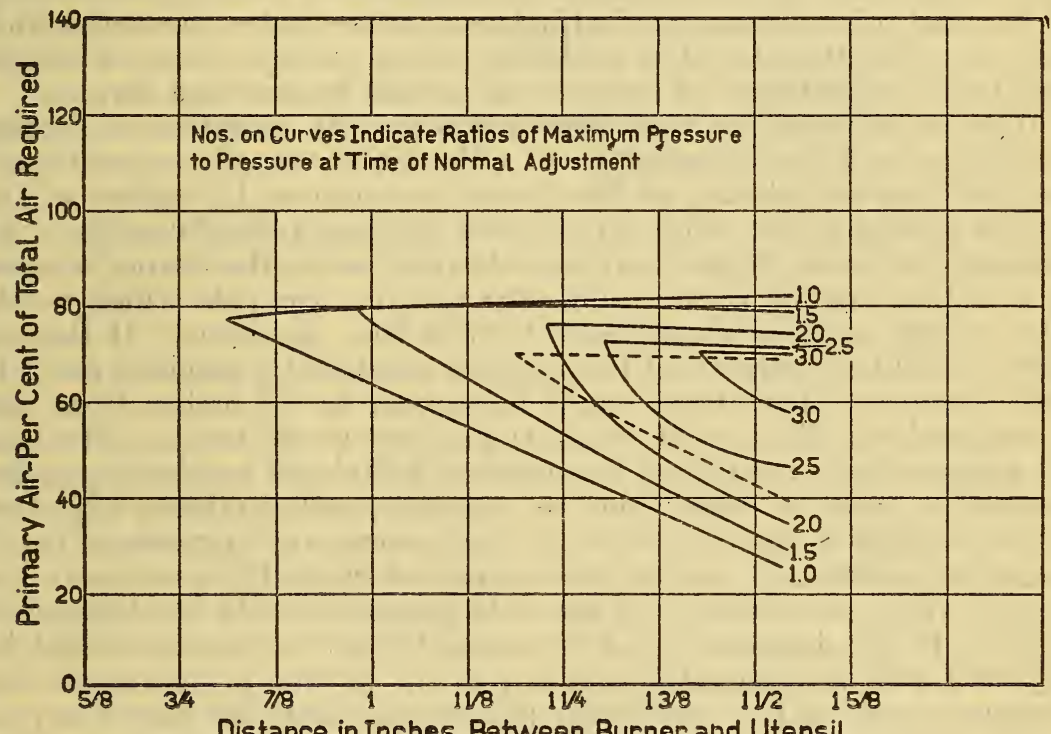

FIGURE 21.-Effect of variations in gas pressure and uncertainties in the adjustment of both gas rate and primary air on the safe range of primary air adjustment and the safe distance between burner and utensil

Probably the most common practice in the adjustment of appliances is for the adjuster merely to set what appears to his practiced eye to be a "good flame," with respect to the quantities of both gas and primary air. The adjustment is made without measurements of any kind; and much worse than this, it is usually made to give the desired result at the pressure which exists when the adjustment is made, without accurate knowledge or consideration of changes of pressure which will take place subsequently. In some cases adjusters are required to make an accurate adjustment of the gas supply to the manufacturer's rating by timing the meter; but this precaution is of little use when the adjuster is working, for example, in the middle of a July afternoon and has no idea whether the pressure on a January morning in that locality is likely to be greater or less than that observed. 
In most cases a gas company endeavors to maintain a pressure which will not vary at any one place by more than 100 per cent of the minimum. Although in many cases it does not succeed in this, the extremes of pressure (both high and low, depending on the distance from the source of supply) usually come during the periods of the morning and evening cooking load. If these periods are avoided when making adjustments, as will usually be the case, it is reasonably safe to assume that the pressure to which the appliance will be subjected after adjustment will not be more than double that at the time of adjustment ( $R$ is not greater than 2$)$. If the adjusters are not instructed to determine the gas rate accurately by means of the meter, a probable error in the estimated rate of at least 10 per cent should be allowed for. This corresponds to about 20 per cent difference in pressure at the pressure of adjustment and approximately 43 per cent of the pressure of adjustment at the higher pressure which may be encountered. It is probable that a range of error of 20 per cent in the adjustment of primary air should be provided for.

When allowance has thus been made for the variation of service conditions and the uncertainty of adjustment usually encountered we find that the placing of the burner as close as $1 \frac{1}{2}$ inches to the utensil is hardly safe, while any shorter distance is inadmissible. An efficiency of about 40 per cent was obtained when the burner was set at a distance of $1 \frac{1}{2}$ inches, and adjusted at a gas rate which would allow a rate of heat absorption of $2,700 \mathrm{Btu}$. per hour. If the designer could be assured that the adjuster would set a specified gas rate with accuracy, the burner could be moved to $1 \frac{3 / 8}{8}$ inches from the utensil and an efficiency of about 41 per cent would result. If either the pressure were controlled by means of individual regulators, or gas companies could be relied upon to maintain, and appliance adjusters to use, adequate pressure surveys, the uncertainty of pressure could be largely eliminated and the burner moved up to $1 \frac{1}{8}$ or at most $11 / 16$ inches, where an efficiency of about 44 per cent would be obtainable. Finally, if the designer could be assured that the burner would be adjusted with instrumental accuracy at the normal pressure and this pressure would not be exceeded, the burner could be placed seveneighths inch from the utensil and an efficiency of approximately 50 per cent (obtained by extrapolation) would be practicable.

\section{ACKNOWLEDGMENTS}

The method of experimental study described in this paper has been developed gradually during the varied work of several years. During this time the authors have been ably assisted in collecting data by the following men: John Corsiglia, R. W. Heywood, Oscar Tow, G. H. Cash, Otto Lutherer, N. L. Miller, B. D. Jenkins, and C. J. Merritt, all research associates from the American Gas Association Testing Laboratory; and S. A. Guerrieri, S. L. Earle, C. Creitz, W. Criswell, J. H. Branham, and H. W. Bailey, of this bureau. 


\section{APPENDIX}

1. AN OUTLINE OF THE IODINE PENTOXIDE METHOD FOR DETERMINING SMALL QUANTITIES OF CARBON MONOXIDE IN THE PRODUCTS OF COMBUSTION

The determination of the amount of carbon monoxide present in the products of combustion is important as a criterion of the completeness of combustion and of the safe operation of gas appliances. The apparatus here described is a modification of one designed and used by the Chemical Warfare Service during the war. This method is based on the reaction of carbon monoxide (CO) and iodine pentoxide $\left(\mathrm{I}_{2} \mathrm{O}_{5}\right)$ which results in the liberation of iodine and the formation of carbon dioxide according to the equation $\mathrm{I}_{2} \mathrm{O}_{5}+5 \mathrm{CO}=\mathrm{I}_{2}+5 \mathrm{CO}_{2}$. The liberated iodine is absorbed in potassium iodide (10 per cent solution) and the amount determined by titration with a standardized solution of sodium thiosulphate $\left(\mathrm{Na}_{2} \mathrm{~S}_{2} \mathrm{O}_{3} .5 \mathrm{H}_{2} \mathrm{O}\right)$. Since the amount of liberated iodine and the volume of sample passed through the apparatus are known, the amount of carbon monoxide in the products of combustion (as sampled) can be calculated. Because the samples usually contain various amounts of excess air, it is necessary to compute the results to an air-free basis in order to compare various tests. The amount of excess air may be computed by determining free oxygen; but it is usually more convenient in routine work to determine the amount of carbon dioxide and the total volume of products, including nitrogen, formed by the combustion of a unit volume of gas, and to subsequently determine only carbon monoxide and carbon dioxide in the samples taken.

Figure 22 shows the details of construction of the iodine pentoxide apparatus designed at the Bureau of Standards. $A$ is a nichrome wound resistance furnace heating a porcelain tube of about $7 \mathrm{~mm}$ inside diameter filled with palladium asbestos. The furnace should heat this tube to a temperature of about $700^{\circ}$ to $750^{\circ} \mathrm{C}$. $B$ is a mercury sealed trap containing just enough mercury to cover the tip of the tube $C . \quad D$ is a float valve. The hollow, ground glass ball $E$ must rise in water and seat with certainty. $F$ is a specially made wash bottle of the Greiner-Friedrichs type. It is filled with concentrated sulphuric acid approximately saturated with potassium bichromate at room temperature. The liquid is introduced through the funnel marked " $G$," which connects with the bottom of the wash bottle, as does also the tube $H$ through which the wash bottle is emptied. The V-shaped tube, $I$, is filled with phosphorus pentoxide and so designed that it can be easily filled or emptied without removal from the train. $J$ is a tube containing iodine pentoxide supported on glass wool. $K$ is a Gomberg absorption bulb, and $L$ is a second mercury trap similar to $B$. $M$ is an air bath insulated with approximately one-half inch of silocel, for the immersion of the absorber $F$. It is heated by means of an electric heating coil wound around the interior of the container, and capable of heating the air to a temperature of $100^{\circ} \mathrm{C}$. $N$ is another insulated air bath heated to a temperature of about $150^{\circ} \mathrm{C}$. The temperature of both of these air baths can be controlled by means of variable external resistances.

Briefly, the operation of the iodine pentoxide apparatus is as follows: The sample is drawn into the train at $D$ by means of suction applied

$117348-32-3$ 
at the outlet of mercury $\operatorname{trap} L$. The water used to displace the sample from the sampling tube ultimately acts upon the float $E$, causing it to rise to its upper seat. This automatically cuts off the flow through $D$. As long as the sample is flowing in at $D$ the mercury in the trap $B$ is sufficient to keep air from entering at $A$, but as soon as the float closes this mercury seal is broken and air for purging

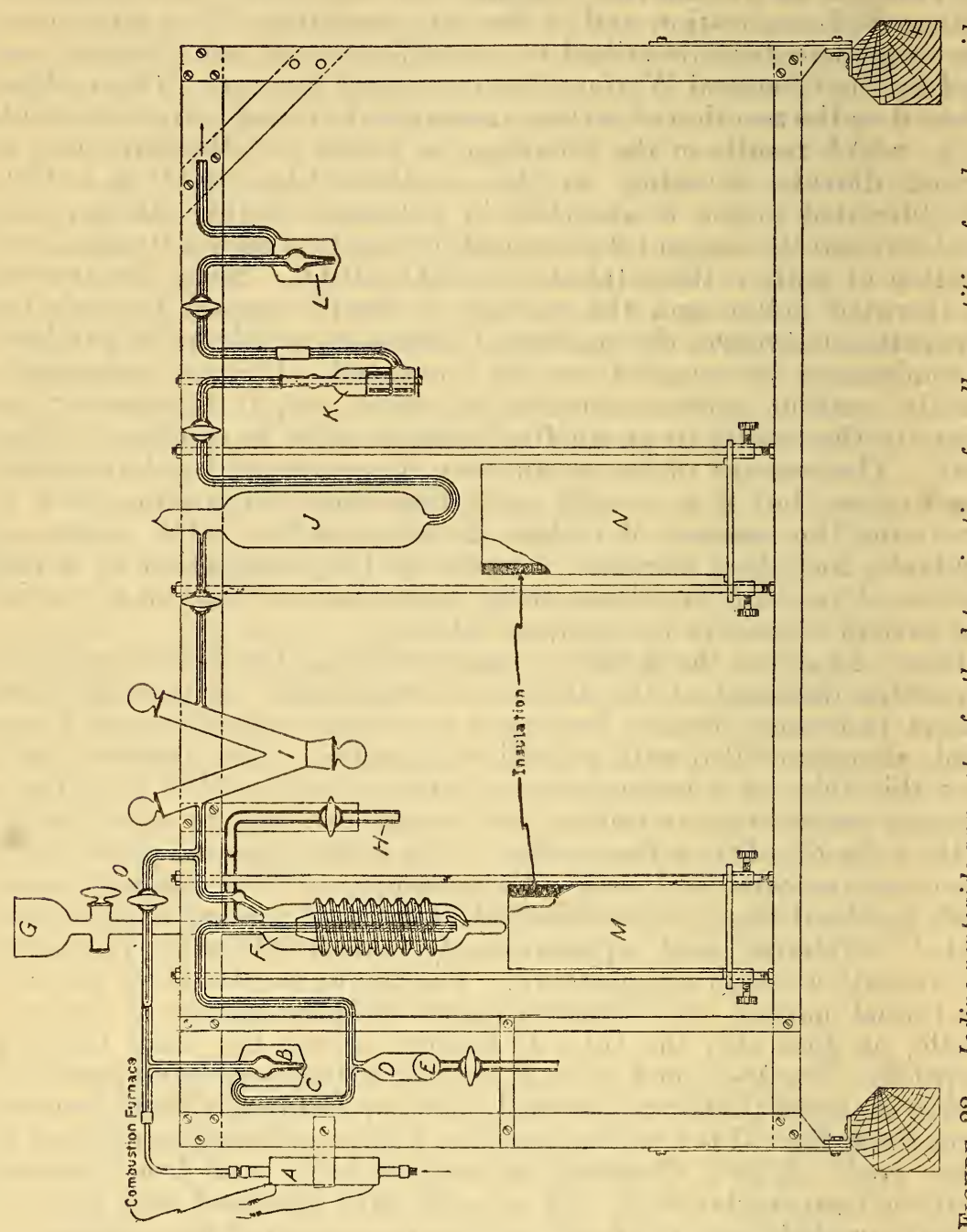

the train enters through the electric furnace, where any traces of carbon monoxide which might be present are burned to carbon dioxide. If the room air is free from carbon monoxide, or if air from outside can be used, this furnace can be dispensed with. It is also possible to purge the train with some inert gas, such as nitrogen, which can be supplied from a cylinder. From $D$ the sample passes through wash bottle $F$, where the hot chromic acid oxidizes any materials other than carbon monoxide which are likely to be present 
and which will reduce iodine pentoxide. Sulphur dioxide, hydrogen sulphide, ethylene; and some other substances are quantitatively removed by such a solution at $100^{\circ} \mathrm{C}$. Carbon monoxide is not affected. This absorber also serves to remove all but a little of the water vapor. From $F$ the sample passes into $I$, where the phosphorus pentoxide removes the remaining water vapor, as well as any acid spray which might have come over from $F$. In $J$ the carbon monoxide reacts with the iodine pentoxide, as stated in the equation above; the iodine and carbon dioxide which are liberated pass into the Gomberg bulb $K$, where the iodine is absorbed by the potassium iodide solution. After the sample has been passed through the apparatus the train is purged with air long enough to insure that all of the sample has passed into $J$ and the iodine liberated all swept into the absorption bulb. The stopcock at the outlet of $K$ is closed and the pressure in the system brought to atmospheric by opening the by-pass cock $O$. The Gomberg bulb is then removed, its contents transferred to a flask and titrated with sodium thiosulphate, using starch as an indicator.

It is necessary to make sure that no iodine is being liberated before the sample is introduced into the train. 'This is done by purging with air for the same length of time as is necessary for the analysis of the sample, and then adding a few drops of the indicator to the contents of the Gomberg bulb. If no blue color appears the apparatus is ready for use.

This method is suitable for analyzing samples containing less than 1 per cent of carbon monoxide. The method comprises a direct determination of the amount of carbon monoxide, and it is therefore used to calibrate other types of apparatus used for carbon monoxide determinations. Its chief disadvantages are the time required for making a determination (about one half-hour) and the continual care necessary to keep the apparatus in running order. It is sensitive to amounts of carbon monoxide as small as 0.001 per cent, and its precision is about 0.003 per cent by volume. The usual sample for small amounts of carbon monoxide is $500 \mathrm{ml}$.

\section{APPLICATION OF THE THERMAL-CONDUCTIVITY METHOD OF GAS ANALYSIS TO THE STUDY OF GAS APPLIANCES ${ }^{9}$}

The analysis of gases by the "thermal-conductivity method" is based on the following principle: Assume a wire to be surrounded by a gas which is contained in a chamber the walls of which are maintained at a constant temperature. When a source of constant electromotive force is applied to the wire its temperature rises above that of the walls until a steady state is reached in which the rate of heat transfer from the wire to the walls is equal to the rate at which heat is generated by the current in the wire. The energy is dissipated by radiation, by conduction through the connections to the ends of the wire, by currents of gas circulating in the atmosphere surrounding the wire, and by conduction through the gas. Some heat is also carried away by the current of gas in case there is a flow of gas past the wire.

By a proper arrangement of conditions, all heat losses except by conduction through the gas surrounding the wire can be reduced 
to a minimum. The most important loss, that by convection, is largely eliminated by making the inside diameter of the cell about $1 \mathrm{~cm}$. Under such conditions, it is evident that the equilibrium temperature attained by the wire will depend mainly upon the ability of the gas which surrounds the wire to conduct heat, this temperature being lower when the gas has a high conductivity, and higher

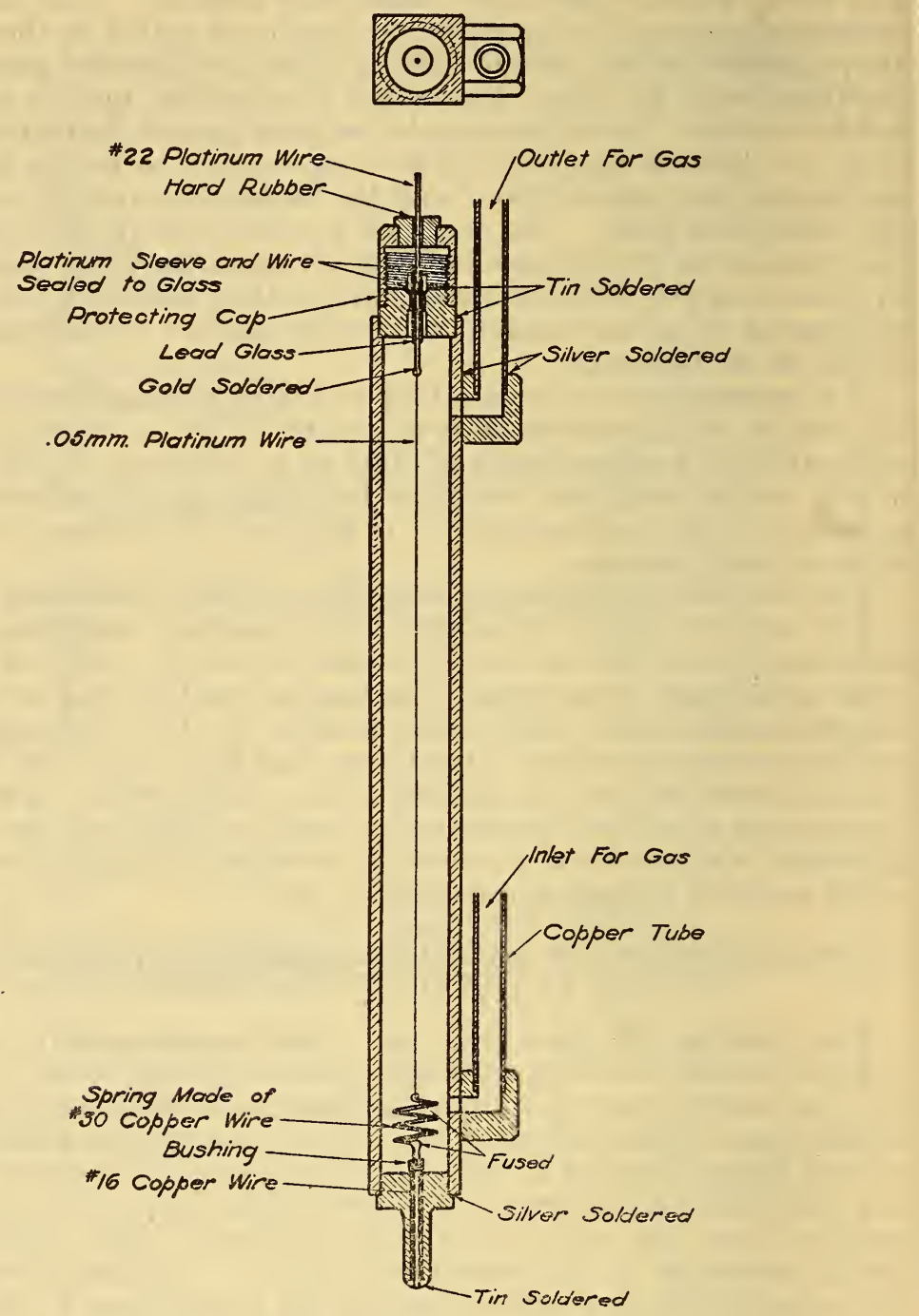

Figure 23.-Section of thermal conductivity unit

when the gas has a low conductivity. If the wire used has a high temperature coefficient of electrical resistance, the resistance will vary measurably with the thermal conductivity, and therefore with the composition of the surrounding gas. By the comparison of the resistances of two such wires mounted in suitable cells and surrounded respectively, by a reference gas and a mixture of two gases of which 
the qualitative composition is known, the quantitative composition of the mixture can be rapidly and accurately determined after an empirical calibration has been made. Figure 23 is a longitudinal section through a cell showing the details of construction.

As a convenient method for comparing the resistances of the two wires, a shunted slide wire provided with extension coils is connected in parallel with the two wires of the thermal conductivity cells to form a balanced Wheatstone bridge. The apparatus employed is represented diagrammatically in Figure 24. By choosing suitable shunts and end coils, the instrument may be made to have the range and sensitivity most favorable for the measurements to be made. One terminal of a galvanometer is joined to the common connection between the two cells, and the other terminal is connected to the contact of variable position on the slide wire.

If accurate measurements are to be made, the walls of the cells must be maintained at a constant temperature. This may be done

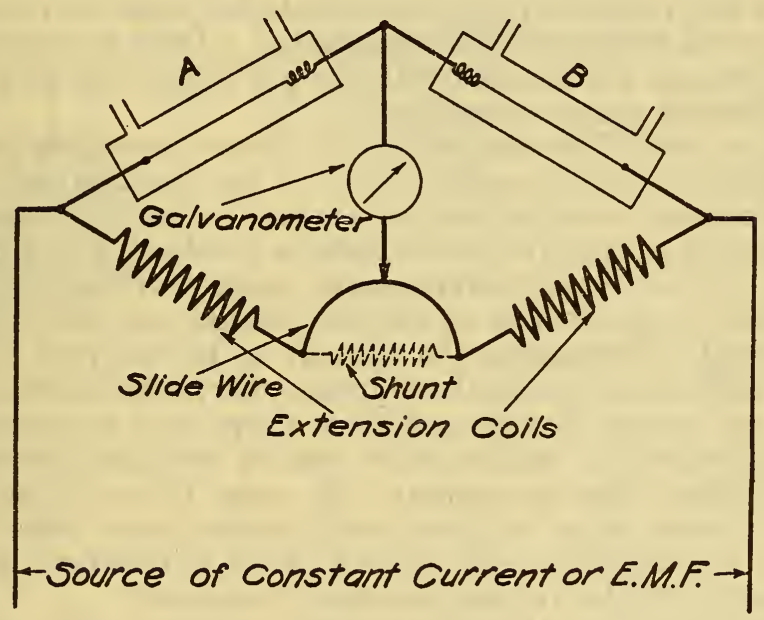

Figure 24.-Wiring diagram of the air-gas ratio

by immersing them in an oil bath, kept at constant temperature, or by clamping them in a metal block which is kept at constant temperature by means of a bimetallic strip thermostat.

The applications of the method of interest in connection with this paper are the determination of the relative proportions of gas and air in burners and the determination of carbon monoxide and carbon dioxide in products of combustion from gas appliances.

The first of these applications is extremely simple and consists in comparing the mixture in the burner, which is drawn into one cell, with a standard gas (usually air) sealed in the other cell. Figure 25 shows a photograph of the apparatus as used. The only complication arises from the fact that the composition and conductivity of manufactured gas change from time to time so that a simple calibration of the apparatus with mixtures of air and the gas made at one time will not accurately represent the composition of mixtures of air with the gas made at another time. This difficulty is readily overcome, however, by consideration of the following facts. If $A$ represents the 
reading of the instrument when air is in the analyzing cell, $G_{1}$ represents the reading when the analyzing cell is filled with one gas unmixed with air, $G_{2}$ represents the reading when the cell is filled with another gas likewise unmixed with air, and $R_{1}$ and $R_{2}$ represent the readings when the cell is filled with air mixed with the respective gases in the same proportion in the two cases, the following relation prevails.

$$
\frac{A-G_{1}}{A-G_{2}}=\frac{A-R_{1}}{A-R_{2}}
$$

From this equation and a calibration curve for a gas giving one scale reading when unmixed with air, it is easy to construct a calibration curve for a gas which gives any other scale reading. If the apparatus is to be extensively used it is advisable to construct a series of calibration curves for gases which give various readings; it is then possible to interpolate between the curves with considerable accuracy for a gas of any conductivity intermediate between the conductivities of gases for which curves were constructed. Only a minute or two is required to sweep out the cell with the gas being used and determine which calibration curve to employ.

For the successful determination of carbon monoxide in products of combustion, certain modifications of the method are necessary. Since the thermal conductivity of carbon monoxide is near that of air, and because of the low concentrations involved, it is impracticable to measure the very small differences in conductivities of the mixtures. The thermal conductivities of carbon dioxide and air, however, are quite different. By passing the mixture to be analyzed through one cell, then through a combustion furnace where the carbon monoxide is burned to carbon dioxide and from there into a comparison cell, greater differences in conductivity can be obtained because of the change in carbon dioxide content. In order to make the apparatus sufficiently sensitive to indicate small percentages (less than a few tenths of a per cent) the cells must be kept at constant temperature in an oil bath and the voltage accurately adjusted.

If the products of combustion contain no combustible constituents, the instrument is balanced at some scale reading (which may be briefly called reading $A$ ), which is nearly but not quite independent of the proportion of other constituents. When combustible gas is present. the position of balance changes from $A$, by an amount $B$ which is proportional to the concentration of combustible present and gives a total reading $A+B$. By reversing the direction of flow of the sample, the gases in the two cells are interchanged and the reading becomes $A-B$. The two readings are compared by taking the difference between them. This is $2 B$ and is independent of changes that affect only $A$.

It is essential when using the apparatus in this manner to have a sample which does not change during this comparison, hence, continuous sampling is not permissible.

From the carbon monoxide unit the gas passes directly into the analysis cell of the carbon-dioxide unit. The comparison cell of this unit is filled with air and hermetically sealed.

A sampling apparatus and gas circuit for this purpose are shown diagrammatically in Figure 26. The gas sample enters through tube 1 , bubbles through the concentrated sulphuric acid to remove 
the moisture, and passes to the filter tower through tube 2. Before collecting a sample for analysis the line should be well purged. This is accomplished as follows: With the sample bottle full of mercury and stopcock $A$ in the position shown in solid lines, purge valve $G$ open, and the vacuum valve $F$ open, the gas enters as before and leaves the tower by tube $\%$. At the $T$ in tube 5 the gas is drawn up and passes through the purge valve and thence to the vacuum line. To collect the sample, the purge and vacuum valves are closed, and stopcock $A$ turned to the dotted position. The vacuum valve $F$ is again opened and the mercury in the sample bottle is drawn into the reservoir through tube 4 , the gas entering through tube 5 . When the reservoir has been filled and the mercury drawn up into tube 3 , the valves are closed and stopcock $A$ turned back to the solid line

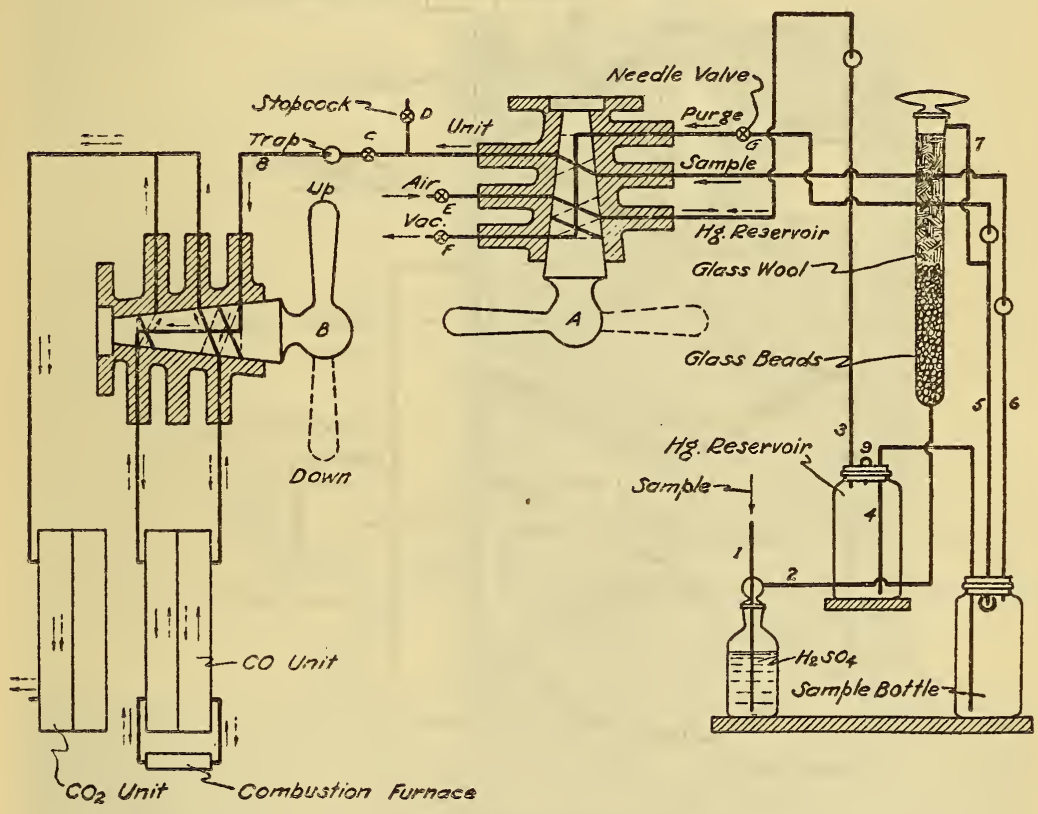

Figure 26.-Flow diagram of apparatus for determining carbon monoxide and carbon dioxide

position. The sample can now be delivered to the thermal conductivity cells by opening the air valve $E$ and line cock $C$. Stopcock $B$ is in either the "up" or "down" position. With this arrangement, atmospheric pressure is exerted on the surface of the mercury in the reservoir, thus forcing the gas sample out through tube 6 , stopcocks $C$ and $B$, and into the cells. With stopcock $B$ in the "up" position, the gas enters the left-hand cell of the carbon-monoxide unit, passes through the combustion furnace, into the right-hand cell, and is discharged from the analysis cell of the carbon-dioxide unit. In the down position, it enters the right-hand cell first and is discharged as before. The solid and dotted arrows indicate the flow for each position. A T and stopcock $C$ are placed in the line directly after stopcock $A$ so that the sample can be wasted, without going through the units, if desired. 
Figure 27 is the wiring diagram of the bridge circuits and Figure 28 is a view of the instrument in use, showing the sampling apparatus on the extreme left.

The apparatus, which has been in continuous use at the Bureau of Standards for the past six years, is sensitive to about 0.002 per cent of carbon monoxide. The determination of carbon dioxide can not be made with quite as great a precision because it is not made by a differential method, but there is no difficulty in making the determination with as great precision and with much greater speed than with any ordinary form of volumetric apparatus.

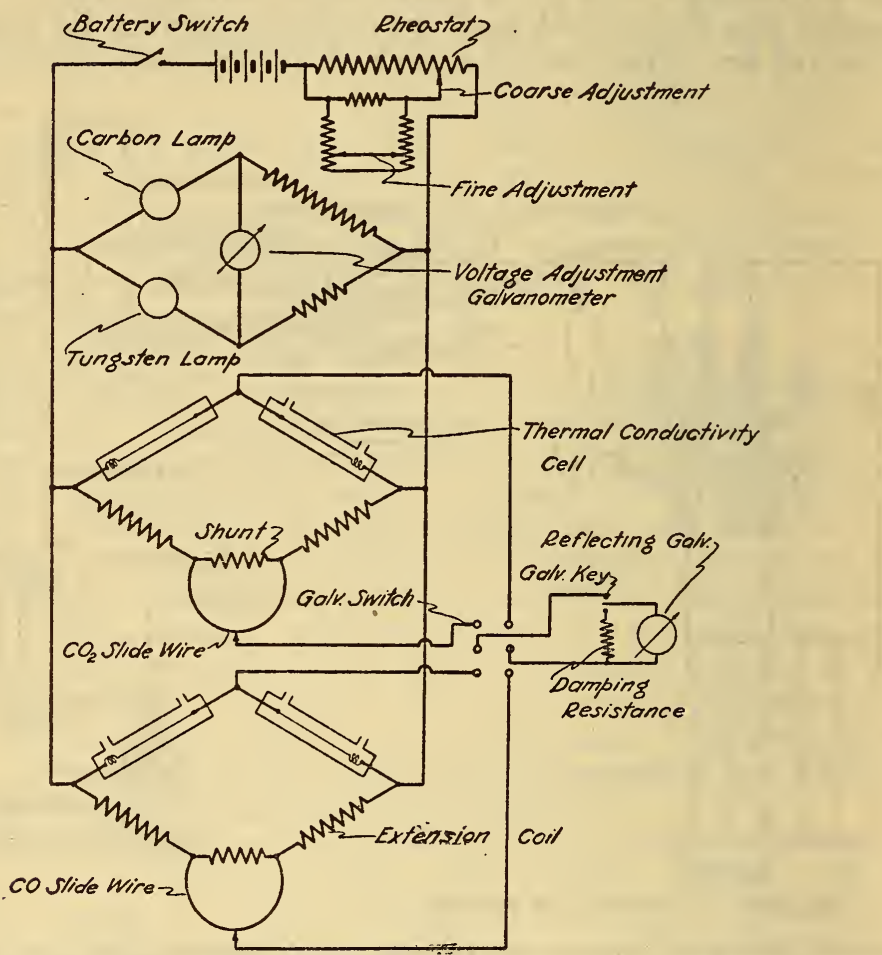

Figure 27.-Wiring diagram of the apparaius for determining carbon monoxide and carbon dioxide

It should be stated that the effect measured when making a carbon monoxide determination depends not only on the carbon monoxide which is converted to carbon dioxide, but also on any other combustible constitutent which may be oxidized in passing through the combustion furnace. In this method of test hydrogen is the most important of these additional constitutents and is always present when the products of combustion contain carbon monoxide. If the ratio of hydrogen to carbon monoxide remained the same, then the conversion of the scale reading to percentage of carbon monoxide for any unknown sample could be made by means of a calibration curve. Such a curve could be obtained by comparing the readings of the thermal conductivity instrument with chemical determinations of carbon monoxide in the same samples, and when once determined would be 


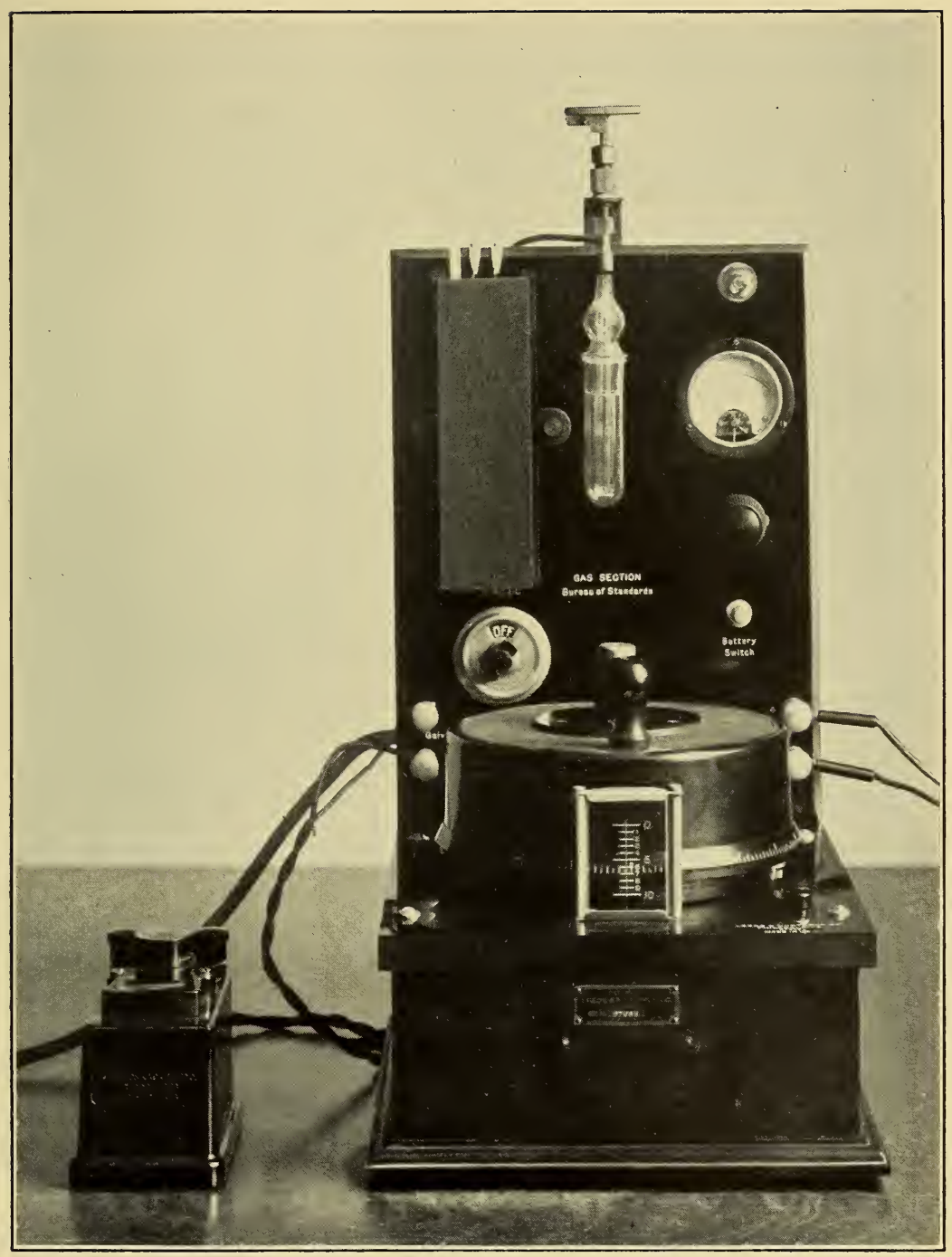

Figure 25.-Air-gas ratio apparatus 
B. S. Journal of Research, RP446

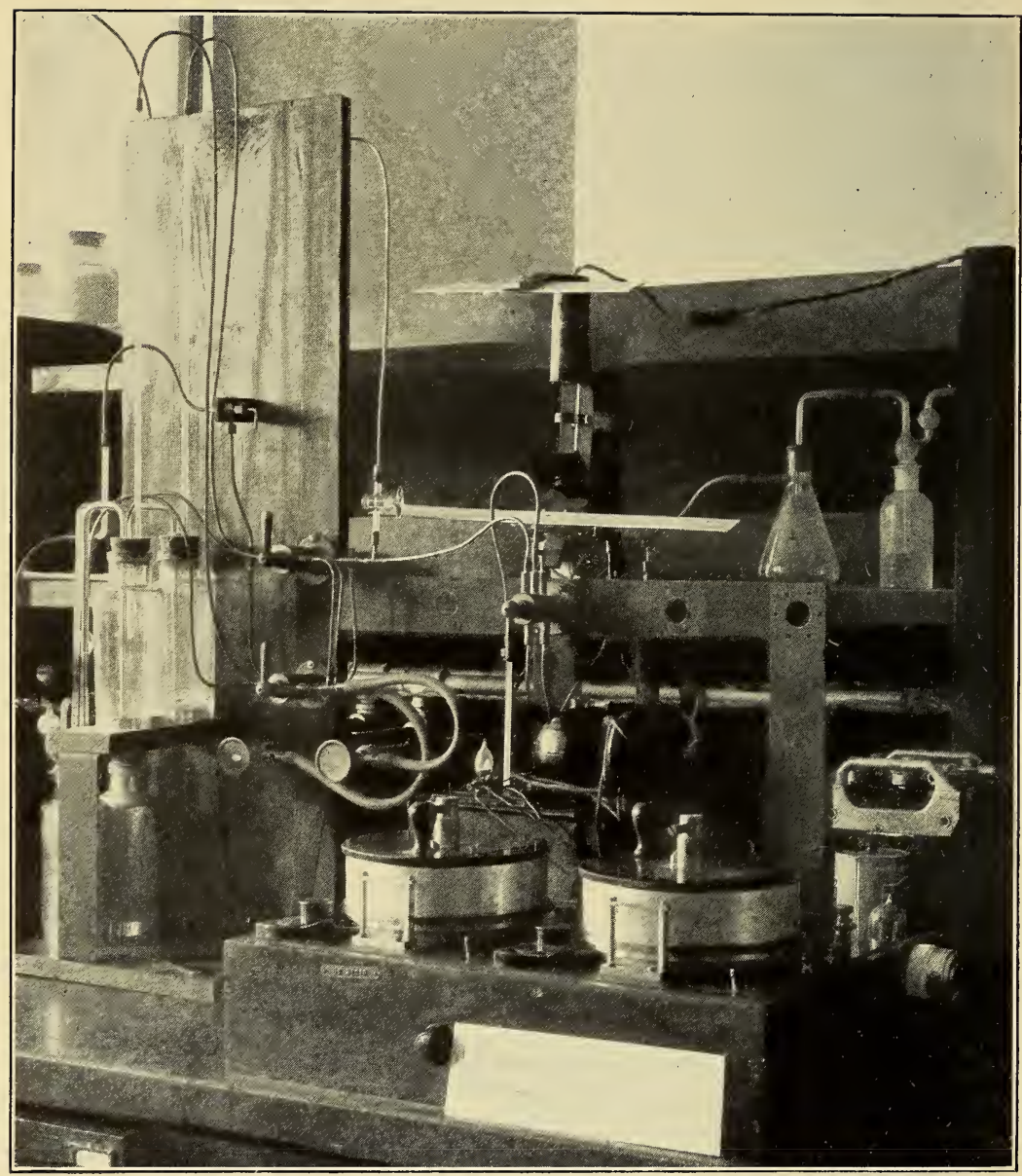

Figure 28.-Apparatus for determining carbon monoxide and carbon dioxide 
applicable to a sample from any fuel gas or type of appliance. Unfortunately, however, the ratio of hydrogen to carbon monoxide does not remain constant, but varies with different mixtures of air to gas and also varies with different appliances. A given scale reading on the thermal apparatus does not, therefore, indicate a definite percentage of carbon monoxide, but a variable amount, depending upon the ratio of hydrogen to carbon monoxide in the sample tested. However, the nearly complete combustion of gas in the presence of fairly high primary air ${ }^{10}$ results in a fairly satisfactory calibration curve for amounts of carbon monoxide up to several hundredths of 1 per cent. Smoky flames give low results and the escape of raw gas usually gives high ones.

For the reasons given this method of test is used only where approximate determinations of carbon monoxide are desired, or in tests similar to those described in this paper where the limits of complete combustion ("0 per cent carbon monoxide curves") are required.

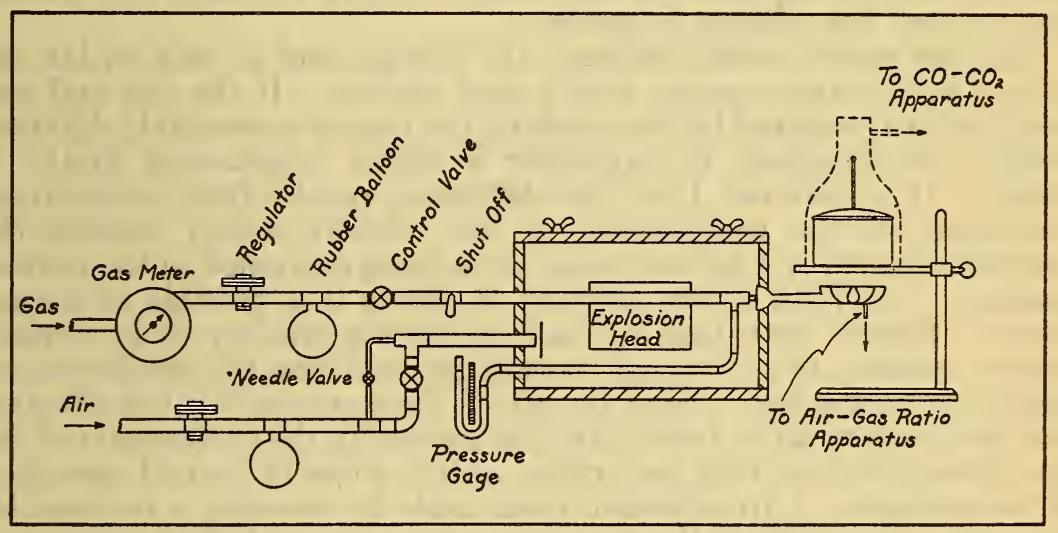

FIGURE 29.-Diagram of burner testing apparatus

3. BURNER TESTING APPARATUS USED FOR SUPPLYING VARIOUS ADJUSTMENTS OF GAS AND PRIMARY AIR TO A GAS BURNER

The apparatus used for obtaining the various adjustments of gas and primary air, as well as the arrangement for making efficiency tests, sampling the products of combustion, and the mixture of air and gas within the burner head is shown in Figure 29. The gas after being metered passes through a pressure regulator by means of which it is possible to obtain at the orifice any pressure desired up to the maximum on the line. From the regulator the gas goes through a control valve of the gate type, which is used to obtain a rough pressure setting, the final setting being made by means of the regulator. A plug cock following the control valve permits the gas to be turned off suddenly without changing the adjustment of the control valve and is particularly useful during flash-back determinations. When the flame flashes back into the burner, the gas must be immediately shut off in order to extinguish the gas which will then be burning at

${ }_{10}$ Incomplete combustion results in this case from insufficient secondary air or the loss of heat from the flame before reaction is completed. 
the orifice. When the plug cock is again turned on, the original pressure adjustment will be duplicated without any further readjustment and enables a check test to be made more conveniently. From this cock the gas passes directly to the gas orifice and issues into the burner. A connection to a pressure gauge is made just ahead of the orifice. A rubber balloon attached to the line by a $T$ between the regulator and control valve serves to eliminate the pressure fluctuations caused by the gas meter and regulator and produces a steadier flow of gas to the burner.

The air passes through a regulator, past a rubber balloon similar to the one on the gas line, and through two valves into an air-tight box where a baffle placed in front of the inlet breaks up the stream. The air supply to the box is controlled by means of two valves placed in parallel, one gate valve by means of which a rough adjustment is made and the other a needle valve for the final adjustment. The only outlet from the box is through the burner, the mixer of which is securely fastened into the box as shown. The gas and primary air mix in the mixing tube of the burner before reaching the burner ports where the mixture is ignited.

The box serves a dual purpose: (1) The gas and air mix within the burner in the same manner as in actual service. If the gas and primary air are premixed before reaching the burner measurably different results are obtained; in particular a higher "flash-back limit" is found. It is believed that this difference results from momentary variations in the composition of the mixture which reaches the individual ports of a burner when air is being entrained in the normal manner. (2) With a box designed as shown it is possible to change from a "forced" test; that is, one in which the primary air is supplied under pressure, to a "normal" operating condition by merely removing the lid of the box. With the lid off, the gas supply is not affected, but the primary air is drawn into the burner by the momentum of the gas stream issuing from the orifice, as it is when in normal operation in an appliance. An explosion head made by covering a rectangular opening on one side of the box with a piece of shellacked paper protects the gas meter and regulators from possible damage when flash back occurs. Ordinarily, flash back does not damage this paper, but it is a useful safety valve and is easily replaced. A copper sampling tube connecting the burner with the air-gas ratio apparatus permits a sample of the air-gas mixture within the burner head to be taken, and the composition of the mixture to be determined for any given adjustment.

An adjustable grid serves to support a utensil at any desired distance above the burner. When a sample of the products of combustion is desired, a hood designed as shown is placed over the utensil and is supported by the grid. This hood is connected directly to the apparatus for determining carbon monoxide and dioxide by means of copper tubing.

A summary of the various uses which can be made of such an apparatus follows:

1. Any desired mixture of air and gas can be supplied to a burner at any reasonable rate.

2. The exact conditions under which flash back, lifting, or yellow tips occur can be determined for any given burner. 
3. It is possible to study the effect on either the efficiency or completeness of combustion of changing such adjustments as gas rate, primary air injection, or distance between burner and utensil.

4. Normal air-injection curves can be obtained by merely removing the lid of the box.

5. The effect of changing pressure on the gas rate can be obtained.

6. The variation of air injection with orifice size or design can be easily determined.

7. By making a complete set of determinations, such as those described in this report, it is possible to compare different gases when using the same burner, or different burners when using the same gas.

Washington, March 19, 1932. 